\title{
Optimization Design of Lattice Structures in Internal Cooling Channel of Turbine Blade
}

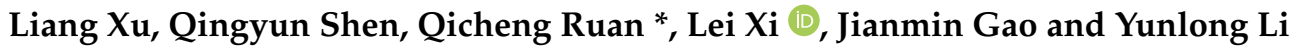 \\ State Key Laboratory of Mechanical Manufacturing Systems Engineering, Xi'an Jiaotong University, \\ Xi'an 710049, China; xuliang@mail.xjtu.edu.cn (L.X.); sqy2017@mail.xjtu.edu.cn (Q.S.); \\ xilei100@mail.xjtu.edu.cn (L.X.); gjm@mail.xjtu.edu.cn (J.G.); ylongli@mail.xjtu.edu.cn (Y.L.) \\ * Correspondence: ruanqicheng93@stu.xjtu.edu.cn; Tel.: +86-136-3670-7323
}

Citation: Xu, L.; Shen, Q.; Ruan, Q.; Xi, L.; Gao, J.; Li, Y. Optimization Design of Lattice Structures in Internal Cooling Channel of Turbine Blade. Appl. Sci. 2021, 11, 5838. https://doi.org/10.3390/app11135838

Academic Editor: Francesca Scargiali

Received: 24 May 2021

Accepted: 17 June 2021

Published: 23 June 2021

Publisher's Note: MDPI stays neutral with regard to jurisdictional claims in published maps and institutional affiliations.

Copyright: (c) 2021 by the authors. Licensee MDPI, Basel, Switzerland. This article is an open access article distributed under the terms and conditions of the Creative Commons Attribution (CC BY) license (https:// creativecommons.org/licenses/by/ $4.0 /)$.

\begin{abstract}
Recently, the inlet temperatures in gas turbine units have been drastically increased, which extremely affects the lifespan of gas turbine blades. Traditional cooling structures greatly improve the high temperature resistance of the blade; however, these structures scarcely concern both heat transfer and mechanical performances. Lattice structure (LS) can realize these requirements because of its characteristics of light weight, high strength, and porosity. Although the topology of LS is complex, it can be manufactured with the 3D metal printing technology. In this study, an integral optimization method of lattice cooling structure, used at the trailing edge of turbine blades, concerned with heat transfer and mechanical performance, was presented. Firstly, functions between the first-order natural frequency (freq1), elasticity modulus $(E)$, relative density $(\bar{\rho})$, and Nusselt number $(N u)$, and the geometric variables of pyramid type LS (PLS) and X-type LS (XLS) were established, and the reliability of these functions was verified. Then, a mathematical optimization model was developed based on these functions which contained two selected optimization problems. Finally, relations among objectives were analyzed; influence law of geometric variables to objectives were discussed, and the accuracy of the optimal LS was proved by experiment and numerical simulation. The optimization results suggest that, compared to the initial LS, $N u$ increases by $24.1 \%$ and $\bar{\rho}$ decreases by $31 \%$ in the optimal LS of the first selected problem, and the $N u$ increases by $28.8 \%$ while freq 1 and $\bar{\rho}$ are almost unchanged in the optimal LS of the second selected problem compared to the initial LS. This study may provide a guidance for functions integration design of lattice cooling structures used at turbine blades based on $3 \mathrm{D}$ printing.
\end{abstract}

Keywords: lattice cooling structure; heat transfer and mechanical performances; integral optimization method; functions integration design

\section{Introduction}

The increase of turbine inlet temperature can improve the efficiency of turbomachinery and cause additional damage to turbine blades. To reach higher inlet temperature and protect turbine blades, many cooling structures have been developed, such as lattice structure (LS). For decades, great attention has been paid to LS because of its unique characteristics of high porosity [1,2], ultralight weight [3,4], high specific stiffness and strength [5], and high heat transfer [3,5]. Although traditional cooling structures of turbine blades can greatly improve the cooling efficiency, Han et al. [6] found that the flow resistance coefficient increases rapidly with the improvement of heat transfer capacity in different degrees, and the heat transfer coefficient distribution is inhomogeneous, causing excessive structural thermal stress. In order to solve these issues, Kim et al. [7] studied the heat transfer performance of pyramid-type lattice structure (PLS) by numerical simulation and experiments, and the results showed that PLS had good homogeneity of heat transfer distribution. Yun et al. [8] carried out an experiment to study face-centered cubic LS and found that this LS showed a good thermal performance compared to non-LS channel. Due to the complex topology of LS, metal additive manufacturing technology can easily solve this limit $[9,10]$. 
Numerous studies have been conducted on the mechanical performances of LS, including relative density and specific strength [11,12], effective modulus and Poisson's ratio $[13,14]$, yield strength, buckling strength, and plateau strength [15]. These studies greatly enriched the mechanical theory for LS, supporting the mechanical optimization of LS. Hoang et al. [16] investigated LS with direct multiscale topology optimization method which provided an inexpensive and efficient method to obtain optimal LS. Zhang et al. [17] proposed topology optimization of LS to obtain optimal density distribution of LS. The results showed that the compressive and bending stiffness and energy absorption of the optimal LS improved. Wu et al. [18] provided a novel strengthening method of LS and presented a pyramidal LS with some mechanical performance advantages. Other optimization approaches for LS included semi-automated optimization approach [19] and inverse identification approach [20], which greatly improved the mechanical performances of LS. These studies almost focus on mechanical optimization with single objective for LS. The optimization studies on heat transfer or specific mechanical performance (lightweight, vibration, and bearing load capacity), or both, performances of LS are as follows.

Liu et al. [21] proposed a mathematical optimization method with two objectives of LS, which improved the structural performance of each panel under multiple loading cases and minimized structural mass of LS simultaneously. Valdevit et al. [22,23] optimized the design of various weight, mechanical, and heat transfer performance of LS, and they found that hexagon structure had the optimal comprehensive performance. Chen et al. [24] found that sandwich structure filled with sponge had the strongest absorbing capacity and reached the targets of minimum dimensionless mass and maximum absorbing capacity of LS. Roper et al. [25] investigated and analyzed the PLS and found that compression modulus, compressive strength, and maximum heat flux increased with the increase of density. Su et al. [26] presented a multiparameter optimization approach for lightweight fiber-reinforced polymer (FRP) composite triangular LS under nonlinear structural response constraints and achieved a significant improvement in terms of weight saving. Moon et al. [27] made a comparison among Kagome type LS, PLS, and diamond type LS for high bearing load and lightweight characteristics, and came to the conclusion that Kagome LS had the best performance, which was applied to the wings of unmanned aerial vehicles (UAV). Meng et al. [28] optimized the strength, vibration, and bird impact load of LS and realized the lightweight design of LS, which was applied to blades. Fazilati et al. [29] optimized the hexagonal multilayer honeycomb lattice and reached the targets of maximizing energy absorption, and minimizing impact vibration and overall size. The results showed that the performance of the optimized structure was significantly improved compared to that of the single layer of nonoptimized structure. Xu et al. [30] optimized PLS using a genetic algorithm to reduce weight and improve sound insulation performance, and also studied the effects of materials and upper and lower panel thicknesses on performance. Bailong et al. [31] carried out an optimal design of body-centered cubic (BCC) LS, considering the relative density, initial stiffness, and plastic failure strength. The research showed that, compared to BCC structure, the elastic modulus and yield limit of the optimized structure increased by $121.5 \%$ and $77.3 \%$, respectively. Smardzewski et al. [32] provided the design of optimized or near-optimized LS by experimentally estimating the mechanical strengths and failure mechanisms and found that with the increase of inclination angle of struts and relative density of LS, the mechanical properties of beams increased. Zhao et al. [33] proposed a concurrent optimization method to optimize natural frequencies of additive manufacturing-fabricated LS, which increased the first natural frequency (freq1) of the optimized structure, 38.5\% higher than that of the original structure. Akihiro et al. [34] used a simple basic lattice shape composed of pillars, and only optimized its density distribution by setting the pillar diameter as design variable, and treating steady-state pressure and temperature reductions as multiobjective functions. Adil et al. [35] investigated the optimal designs of novel LS filled with thin tubes based on multiobjective crashworthiness optimization procedure. Lattice member diameter and tube thickness were set as design variables, and minimizing peak crash force and maximizing specific energy absorption 
were chosen as design objectives. The research revealed that the optimized BCC LS hybrid designs generally had a better crashworthiness performance than BCC LS with vertical strut counterparts with the same design objectives.

As outlined above, optimization methods of LS with two or more objectives of mechanical or heat transfer, or both, greatly expanded the application of LS in heat pipes and tubes. However, few studies on optimization method of LS concerned both heat transfer and mechanical performances used at region " 1 " of turbine blades, as shown in Figure 1. Although, in [36], Gao et al. developed an effective optimization method of LS concerning both heat transfer and mechanical performances, the application background was for composite structure instead of turbine blades. Therefore, the aim of this study was to construct an optimization model of PLS and X-type LS (XLS) to obtain the optimal LS used at the trailing edge of turbine blades based on functions establishment between geometric parameters (diameter and inclination angle of LS) and representative parameters (Nusselt number, relative density, the first-order natural frequency, and elastic modulus). The boundary conditions were simplified from turbine blades, such as thin-wall structure; applying a constant heat flux on the target surface; mass flow inlet; and pressure outlet. The results show that the heat transfer and mechanical (lightweight, vibration, and bearing load) performances of the optimal LS are better than that of the initial LS obtained from [36] i.e., $N u$ increases by $24.1 \%$ and $\bar{\rho}$ decreases by $31 \%$ in the optimal LS of the first selected problem; and $N u$ increases by $28.8 \%$ while freq 1 and $\bar{\rho}$ are almost unchanged in the optimal LS of the second selected problem, compared to initial LS.

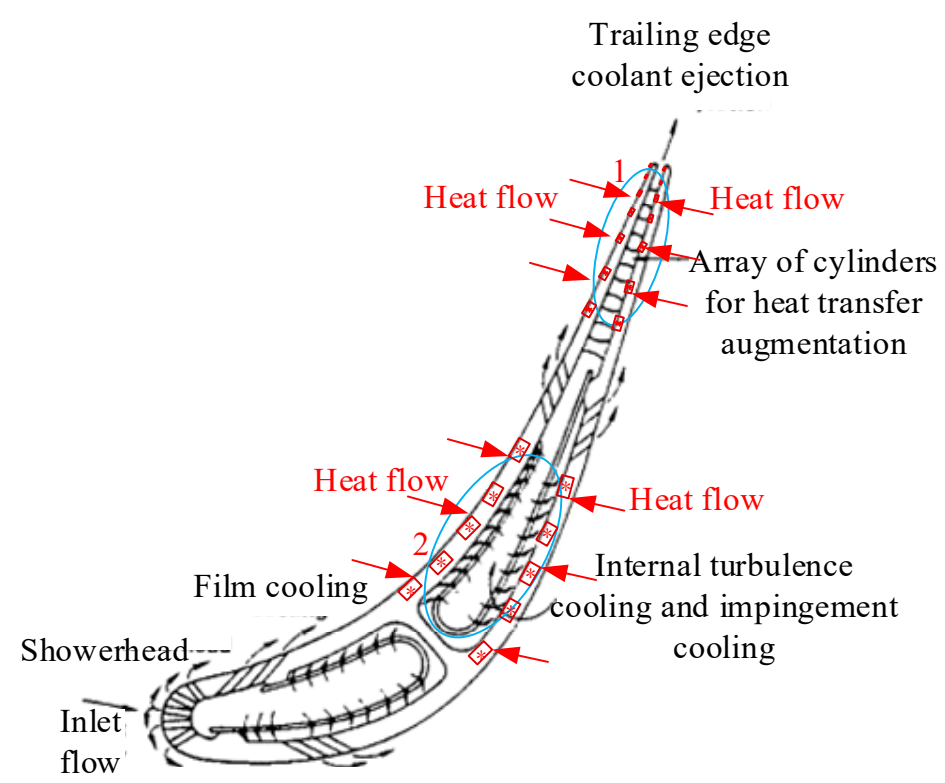

Figure 1. Schematic of cooling arrangement in a turbine blade.

\section{Functions of Heat Transfer and Mechanical Performances}

\subsection{Selected Model}

The schematic of cooling arrangement in a turbine blade is shown in Figure 1. In regions " 1 " and " 2 " are set some traditional internal cooling structures that could improve cooling efficiency and protect the blade from high temperature; however, these structures scarcely concern both heat transfer and mechanical performances. Herein, considering better performances of heat transfer and mechanics, LS was set at thin walls of the blade. Some new internal cooling channels would be established at the thin walls of the blade and LS was placed upon these channels as a component of cooling structure. PLS and XLS used herein are shown in Figure 2. Boundary conditions of LS were given as follows:

In both PLS and XLS, the height of the cooling channel $(H)$ was considered as a constant in order to simplify optimization calculation. The left and right surfaces were velocity inlet and pressure outlet, respectively. The bottom wall was applied with a constant 
heat flux which corresponded to the outer heat source surface of the thin wall of the blade, and was called target surface. Other surfaces of PLS and XLS were adiabatic. Fundamental material of PLS and XLS was nickel-base superalloy IN718 with the density of $8240 \mathrm{~kg} / \mathrm{m}^{3}$, the Young's modulus of $199.9 \mathrm{GPa}$, and the Poisson's ratio of 0.3 (Table 1).

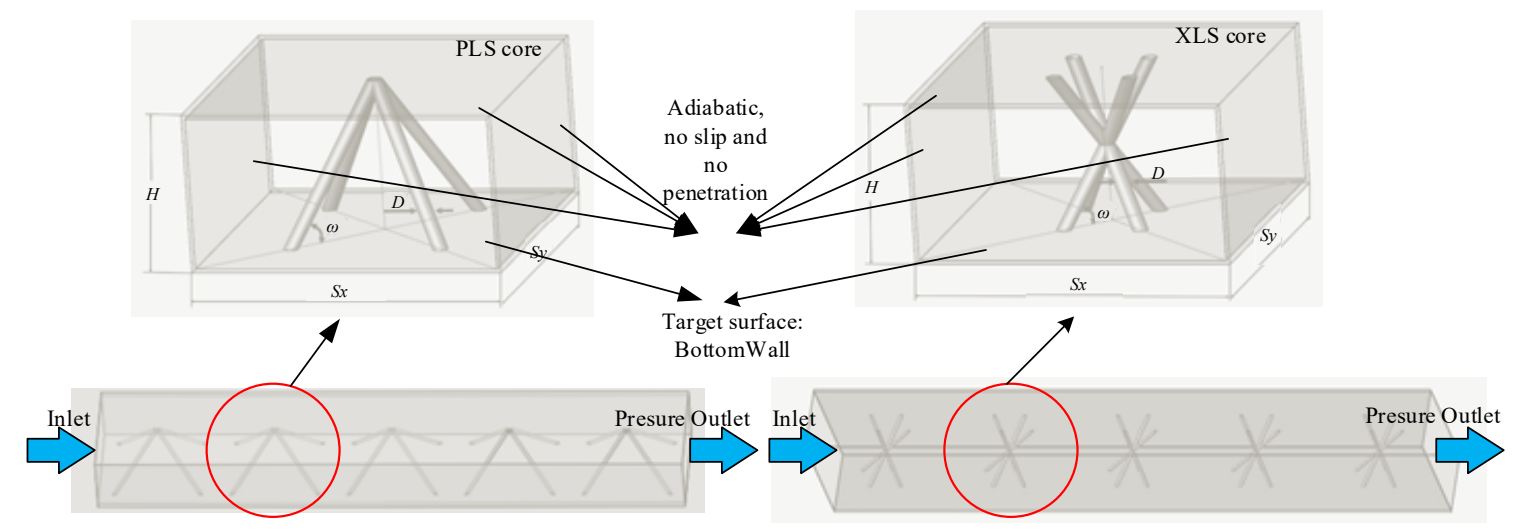

Figure 2. PLS and XLS used in internal cooling channels of blade.

The size of the cooling channel was $80 \times 80 \times 40 \mathrm{~mm}^{3}$. Diameter $(D)$ and inclination angle $(\omega)$ of optimal LS were geometric variables. According to the study shown in reference [36], when $\omega$ of PLS was selected as $45^{\circ}$, the heat transfer performance and mechanical properties of cooling structure were relatively optimum. Therefore, parameters of nonoptimal PLS and XLS (initial LS) were selected as $D=2 \mathrm{~mm}$ and $\omega=45^{\circ}$, as shown in Table 1.

Table 1. Geometric parameters of LS core and its material information.

\begin{tabular}{llll}
\hline Parameter & Value & Parameter & Value \\
\hline Material (used in simulation setting) & & Material (used in experimental validation, printed) & PLA \\
Density & IN 718 & Density & $1240 \mathrm{~kg} / \mathrm{m}^{3}$ \\
Young's modulus & $8240 \mathrm{~kg} / \mathrm{m}^{3}$ & Young's modulus & $4000 \mathrm{MPa}$ \\
Poisson's ratio & $199.9 \mathrm{GPa}$ & Poisson's ratio & 0.3 \\
Geometric parameters & 0.3 & Geometric parameters & $40 \mathrm{~mm}($ initial) \\
Thickness of core walls & $2 \mathrm{~mm}$ & Core height $(H)$ & $2 \mathrm{~mm}($ initial) \\
Core length $\left(S_{y}\right)$ & $80 \mathrm{~mm}$ & Diameter of member $(D)$ & $45^{\circ}($ initial) \\
Core width $\left(S_{x}\right)$ & $80 \mathrm{~mm}$ & Inclination angle of member $(\omega)$ & \\
\hline
\end{tabular}

\subsection{The Function of Heat Transfer Performance}

In the analysis of cooling performance, boundary condition of a constant heat flux was employed [37], which was consistent with the boundary condition of the target surface of the LS selected. In order to characterize the heat transfer performance of LS, the $\mathrm{Nu}$ formula was derived according to the fin method [38].

$\mathrm{Nu}$ is used to evaluate heat transfer performance. Functional relationship between geometric parameters of LS and $N u$ is established:

$$
\begin{gathered}
N u=\frac{h D_{h}}{k_{f}} \\
h=\frac{q}{T_{w}-T_{i n}} \\
D_{h}=\frac{2 S_{y} H}{S_{y}+H}
\end{gathered}
$$


where $h$ is the overall convective heat transfer coefficient of structure, $D_{h}$ is hydraulic diameter, $k_{f}$ is the thermal conductivity of air, $q$ is the average heat flux of the target surface, $T_{w}$ is the average temperature of the target surface, and $T_{i n}$ is the average inlet temperature of air.

Heat transfer of each member in LS channels was considered as the same, so a single member in LS was analyzed. The temperature control equation is as follows:

$$
\frac{d^{2} T_{S}(\eta, n)}{d \eta^{2}}-\frac{h_{\infty} P}{k_{S} S}\left(T_{S}(\eta, n)-T_{f}(n)\right)=0
$$

where $\eta$ is the coordinates along member direction; $n$ is the number of LS cores along the flow direction in LS channel; $T_{f}(\eta, n)$ is the temperature of the $\eta$ coordinate in member of the $n$th row of LS core; $T_{f}(n)$ is the average temperature of air in the $n$th row of LS core; $h_{\infty}$ is the heat transfer coefficient between member surface, and according to the research in literature [39], $h_{\infty}=1.19(R e)^{0.6} ; P$ is the section perimeter of the member; $S$ is the cross-sectional area of the member; $k_{s}$ is the thermal conductivity of the member.

Initial heat flux $\left(q_{0}\right)$ flowed into member from the target surface is calculated:

$$
-\left.k_{s} \frac{d T_{s}}{d_{\eta}}\right|_{\eta=0}=q_{0}
$$

where $q_{0}$ is the heat flux coming from the member in the place of $\eta=0$.

By combining Equations (4) and (5):

$$
T_{s}(\eta, n)-T_{f}(n)=\frac{q_{0}}{k_{s} m} \cdot \frac{\cosh (m(l-\eta))}{\sinh (m l)}
$$

where $l$ is the length of a single member; $l=H / \sin \omega$, and $H$ is the height of the LS channel; $m=2 \sqrt{h_{\infty} /\left(k_{s} D\right)}$, with the dimension of $\mathrm{L}^{-1}$.

When $\eta=0$, the temperature of the member is equal to that of the wall, i.e., $T_{s}(\eta, n)=$ $T_{f}(0, n)=T_{w}(n)$, according to Equation (6):

$$
T_{w}(n)-T_{f}(n)=\frac{q_{0}}{k_{s} m} \cdot \frac{\cosh (m l)}{\sinh (m l)}
$$

From the law of conservation of energy, the following function is obtained:

$$
\rho_{f} S_{y} H u_{m} C_{P}\left[T_{f}(n)-T_{f}(0)\right]=q S_{y} S_{x} n
$$

where $\rho_{f}$ is air density, $u_{m}$ is the average velocity of air, $u_{m}=\operatorname{Re} \mu / \rho_{f} D_{h} ; \operatorname{Re}$ is Reynolds number, $\mu$ is dynamic viscosity of air, and $C_{P}$ is the specific heat capacity of air.

In order to get $q_{0}$, it is necessary to obtain heat flux $q_{1}$ which enters internal fluid directly from the target surface:

$$
q_{1}=h_{1}\left[T_{w}(n)-T_{f}(n)\right]=\frac{h_{1} q_{0}}{k_{s} m} \cdot \frac{\cosh (m l)}{\sinh (m l)}
$$

where $h_{1}$ is the heat transfer coefficient between air and target surface.

In order to simplify the calculation, thermal resistance between member and target surface is ignored, so $h_{1}$ and $h_{\infty}$ are considered to be the same. Therefore, the heat flux $q$ entering the $n$th row of LS core is:

$$
S_{x} \cdot S_{y} \cdot q=\left(S_{x} \cdot S_{y}-\frac{3 \pi D^{2}}{4}\right) q_{1}+\frac{3 \pi D^{2} q_{0}}{4}
$$


By combining Equations (9) and (10), the following equation can be obtained:

$$
q_{0}=\frac{S_{x} \cdot S_{y} \cdot q}{\left(S_{x} \cdot S_{y} \cdot \frac{3 \pi D^{2}}{4}\right) \cdot \frac{h_{1} q_{0}}{k_{s} m} \cdot \frac{\cosh (m l)}{\sinh (m l)}+\frac{3 \pi D^{2}}{4}}
$$

In conclusion:

$$
h=\frac{q}{T_{w}-T_{i n}}=\frac{q}{T_{w}(n)-T_{f}(0)}=\frac{q}{T_{w}(n)-T_{f}(n)+\frac{q S_{x} n}{\rho_{f} H u_{m} C_{P}}}
$$

By combining Equations (7), (11), and (12), the final equations can be obtained. The formula of $\mathrm{Nu}$ for a single core of PLS is:

$$
N u(n)=\frac{D_{h}}{k_{f}\left(\frac{S_{x} n}{\rho_{f} H u_{m} C_{P}}+\frac{1}{k_{s} m} \operatorname{coth}(m l) \frac{S_{x} S_{y}}{\left(S_{x} S_{y}-\frac{3 \pi D^{2}}{4}\right) \frac{h_{\infty} \operatorname{coth}(m l)}{k_{s} m}+\frac{3 \pi D^{2}}{4}}\right)}
$$

The formula of $\mathrm{Nu}$ for a single core of XLS is:

$$
N u(n)=\frac{D_{h}}{k_{f}\left(\frac{S_{x} n}{\rho_{f} H u_{m} C_{P}}+\frac{1}{k_{s} m} \operatorname{coth}(m l) \frac{S_{x} S_{y}}{\left(S_{x} S_{y}-2 \pi D^{2}\right) \frac{h_{\infty} \operatorname{coth}(m l)}{k_{s} m}+2 \pi D^{2}}\right)}
$$

The function of average $\mathrm{N} u$ for a whole LS channel is:

$$
f_{1}(x)=\frac{1}{N} \sum_{1}^{N} N u(n)
$$

where $N$ was 5 , which meant that the whole LS channel had five LS cores. $f_{1}(x)$ was the first objective. This function was validated as follows. Material used in the simulation was IN 718, as shown in Table 1.

It can be observed from Figure 3 that with the increase of $R e$, the trend for the growth of $\mathrm{Nu}$ was consistent between the experiment value of Kim [38] and the calculated value of PLS channel with the fin method. Meanwhile, the maximum error between the calculated value with the fin method and the experiment value of Kim [38] was approximately $17 \%$. Therefore, the given function of $\mathrm{Nu}$ was reliable.

Furthermore, compared with 5 LS cores, when 10 LS cores were set, the average $\mathrm{Nu}$ decreased about $23.1 \%$; when 15 LS cores were set, the $\mathrm{Nu}$ decreased about $47.9 \%$. Therefore, five LS cells were set in flow direction of LS channel to reduce the overall size and improve heat transfer performance of the cooling structure, as shown in Figure 2. Generally, the pressure drop of the cooling channel gradually increases with the increase of $R e$. However, when $R e$ reached up to 10,000, the pressure drop was only around $300 \mathrm{~Pa}$. In addition, the changing $D$ and $\omega$ of LS had little effect on the changing of pressure drop of LS channel. Thus, pressure drop was not further investigated. 


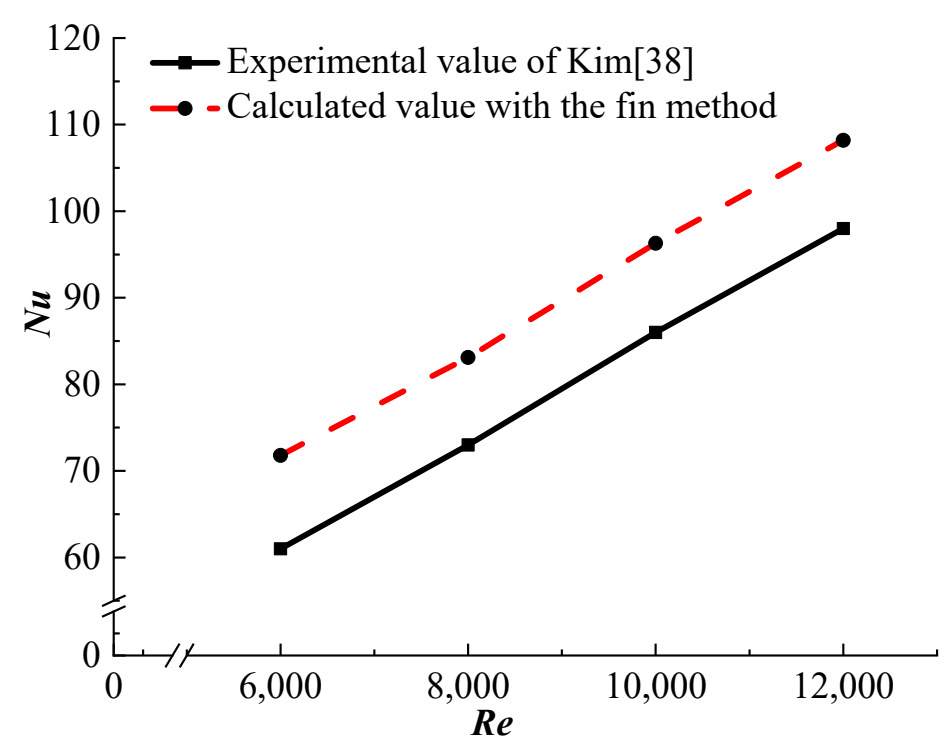

Figure 3. Comparison of the experimental value of Kim [38] and calculated value with the fin method.

\subsection{The Function of Vibration Performance}

Low-frequency vibration and vibration causing structural resonance of turbine blades should be avoided. The natural frequency of turbine blades should be increased. To achieve these objectives, LS cores were set at internal cooling channel of turbine blades, and the finite element analysis method (FEA) was used to set up the relevance between the firstorder natural frequency (freq1) and geometric parameters of LS channel. This relevance was determined by an implicit function box by numerical calculation using ABAQUS software.

Therefore, the function of freq 1 can be expressed as:

$$
f_{2}(x)=f r e q 1=f(D, \omega)
$$

This value was given by ABAQUS directly by numerical calculation. The boundary condition of LS channel was fixed support on one side and free on the other side. Herein, vibration of PLS channel and XLS channel were mainly investigated. However, the XLS had symmetrical characteristic in topology. Therefore, the value of Equation (16) was based on the XLS channel as well as this value validation. $f_{2}(x)$ was the second objective, and this function was validated as follows.

The XLS channel is shown in Figure 4a. Material used for the printed XLS channel was PLA, as shown in Table 1. The modified quadric tetrahedron element (C3D10M) was used in the process of mesh generation. After the verification of grid independence, the first six-order natural frequencies (freq1-6) tended to be stable when the grid number was approximately 100,000. Therefore, the computational grid number of the XLS channel was approximately 100,000. Relevant experiments were carried out to further verify the reliability of the finite element results. In the experiment, a SIEMENS SCM205 dynamic signal analyzer was used; the model of force hammer was PCB086C 03 with a sensitivity of $2.25 \mathrm{mV} / \mathrm{N}$; a PCB356A66 piezoelectric accelerometer sensor was used with a sensitivity of $1.034 \mathrm{mV} /\left(\mathrm{m} \cdot \mathrm{s}^{2}\right)$, and a vice was used to fix the test sample so as to reduce its impact on the accuracy of the experimental results. Figure 4a shows the sample of XLS channel and the layout of the relevant measuring points. The sample was divided into five parts in the length direction and two parts in the width direction with equal proportion. The nodes were numbered in sequence, and the geometric model, established in LMS Test.Lab, was consistent with those settings. Acceleration sensors were set at points 5, 11, and 14 of the sample to pick up vibration signals, and a hammer was used to knock at point 17 . The average value was obtained after striking the point five times. The signals were captured by acceleration sensor and force hammer sensor and were transmitted to multi-channel 
data acquisition apparatus for processing. Then, the data were transmitted to PC end for relevant data processing, and the relevant parameters were obtained.

The layout of measuring points

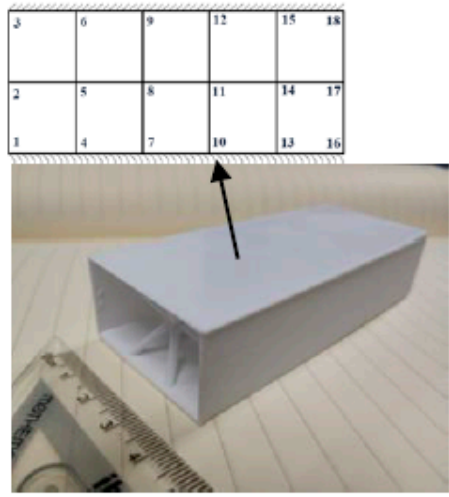

(a) Experimental samples of XLS

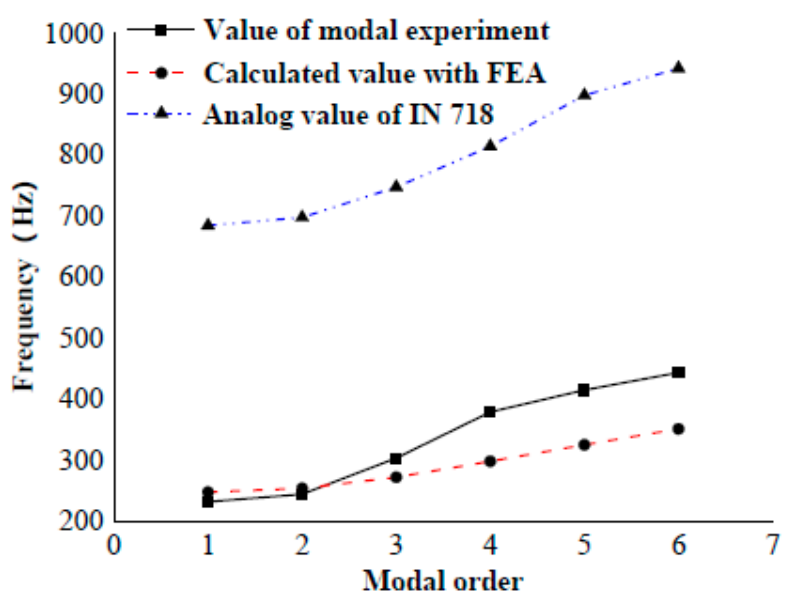

(b) Model experiment value and calculated value

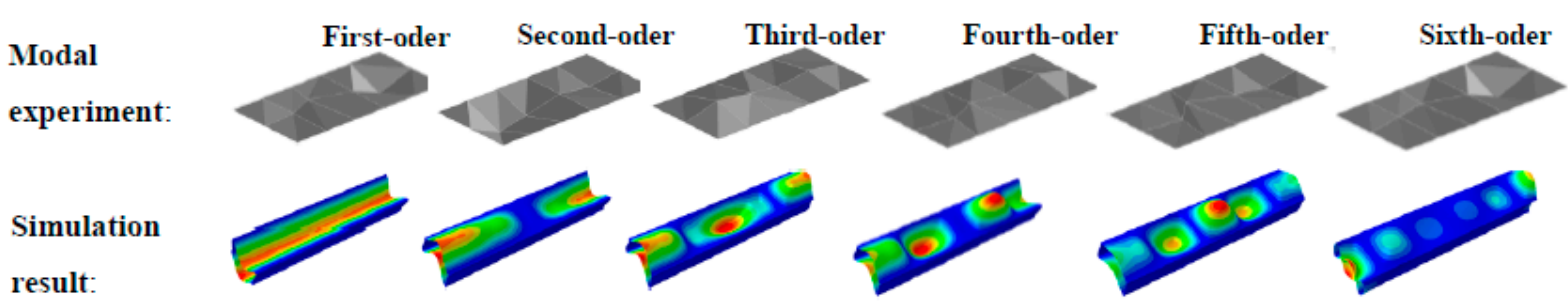

(c) Vibration mode of modal experiment and simulation result

Figure 4. Printed XLS channel and vibration validation: (a) Experimental samples of XLS; (b) Model experiment value and calculated value; and (c) Vibration mode of modal experiment and simulation result.

Figure $4 \mathrm{~b}$ shows that in freq $1-3$, the experimental value and calculated value showed good consistency, of which the maximum error was within $10.5 \%$. However, when it came to freq4-6, the error between them was relatively large, and the maximum error reached $24.9 \%$. The reason for the analysis error lay in two aspects. On the one hand, due to the limitation of printing accuracy of the printer, the printed sample had certain defects. Particularly, the printing mode was adopted without internal support at the top of the channel, which made the resin material on the top of the sample not fit tightly enough. On the other hand, because the sample was a thin-walled structure, it was inevitable that some deformation would occur in the sample fixing with the vice. However, in the simulation process using FEA, there were no defects in the three-dimensional model, and its deformation was not considered when the constraints were applied. Meanwhile, the maximum errors between the modal experimental values and the simulated values caused by some defects of the test piece were $17.7 \%$ and $15.21 \%$, respectively $[40,41]$. Therefore, it can be considered that the error between the experimental value and the simulation value will not greatly affect the subsequent simulation results. Additionally, Figure $4 \mathrm{~b}$ shows that the freq1-6 of IN 718 was basically linear with that of the resin material. Therefore, the experimental results can provide guidance for research of LS channels made by IN 718 .

Figure $4 \mathrm{c}$ presents the mode shapes of modal experiment and simulation results. It showed a good consistency between modal experiment result and simulation result. Therefore, the calculation model of vibration function established by FEA is reliable.

\subsection{The Function of Bearing Load Performance}

Bearing load performance was improved in turbine blades using LS cores. Elastic modulus $(E)$ of the LS channel was used to evaluate its bearing load capacity. The relevance 
between $E$ and geometric parameters of LS core was derived using PLS core, and one member of PLS core was analyzed, as shown in Figure 5. An outer load $F$ was added at the upper end of the member, and the member had a displacement $\delta$, which caused axial force $F_{A}$ and shear force $F_{S}$. As all forces in the member were balanced, $F$ can be obtained along the vertical direction:

$$
F=F_{A} \sin \omega+F_{S} \cos \omega
$$

According to the compression and bending function of the member, $F_{A}$ and $F_{S}$ can be obtained:

$$
\begin{gathered}
F_{A}=E_{c} \frac{\pi D^{2}}{4} \frac{\delta \sin \omega}{l} \\
F_{S}=\frac{3}{4} E_{c} \pi \frac{D^{4}}{16 l^{3}} \delta \cos \omega
\end{gathered}
$$

where $E_{c}$ is the elastic modulus of the material of PLS channel.

The equivalent plane compressive stress and strain can be defined as:

$$
\begin{gathered}
\sigma_{e}=\frac{4 F}{A} \\
\mathcal{E}_{e}=\frac{\delta}{l \sin \omega}
\end{gathered}
$$

where $l$ is the length of the member, as shown in Figure 5, $l=H / \sin \omega . A$ is the area of bottom surface of the PLS core, $A=(\sqrt{2} l \cos \omega+2 t)^{2} ; D$ is the diameter of the member; $t$ is a small spacing between two members at the top wall of the PLS core and also is a small spacing between one of the side walls of the PLS core and the member at the bottom wall of the core.

Combining Equations (20) and (21), the plane elastic modulus of PLS can be obtained:

$$
E=E_{c} \frac{\sigma_{e}}{\varepsilon_{e}}=E_{c} \bar{\rho}_{P} \sin ^{4} \omega+\frac{3}{4} E_{c} \bar{\rho}_{P}\left(\frac{D}{2 l}\right)^{2} \cos ^{2} \omega \sin ^{2} \omega
$$

where $\bar{\rho}_{P}$ is the relative density of the PLS core, and $\bar{\rho}_{P}=\pi D^{2} / \sin (\sqrt{2} l \cos \omega+2 t)^{2}$. As shown in Figure $5 b, D /(2 l)$ is generally a small value; therefore, for Equation (22), the second part can be ignored.

Thus, the equivalent elastic modulus can be expressed as:

$$
E=E_{c} \bar{\rho}_{P} \sin ^{4} \omega
$$

The function of $E$ can be obtained as:

$$
f_{3}(x)=E=E_{c} \bar{\rho}_{P} \sin ^{4} \omega
$$

where $f_{3}(x)$ is the third objective of the present study. Equation (24) is also used for the $E$ value of XLS channel. The Euler buckling critical load of the member is:

$$
\sigma=\frac{k^{2} \pi^{2} E_{c} D^{2}}{l^{2}}
$$

where $k$ is the end restraint factor for buckling.

For LS, due to the large slenderness ratio of the member and the thin panel, the constraint at the end of the member was weak. Therefore, $k$ was taken as 2 , and $f_{3}(x)$ was not used as an objective of the present study, while it was used as a constraint in order to simplify the optimization calculation. 


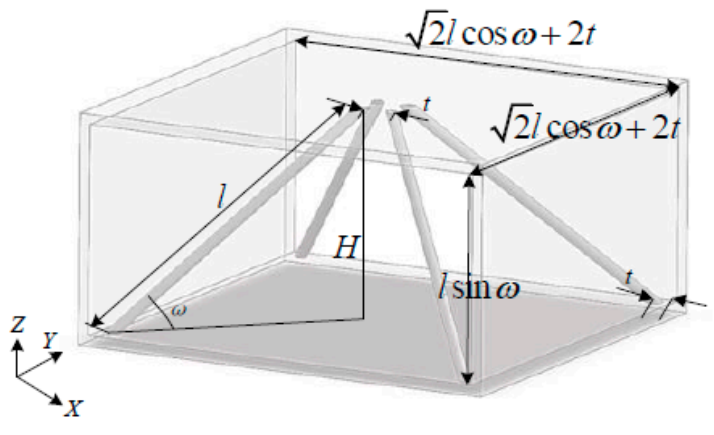

(a) PLS core

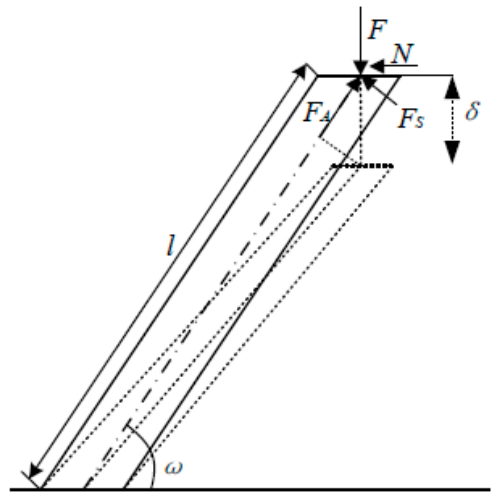

(b) Force analysis

Figure 5. Force analysis of the single member of the PLS core: (a) PLS core; and (b) force analysis.

\subsection{The Function of Lightweight Performance}

Lightweight performance was considered to be improved in turbine blades using LS cores. Relative density $(\bar{\rho})$ of the LS channel was used to evaluate the structural characteristic of being lightweight. The relevance between $\bar{\rho}$ and geometric parameters of PLS channel can be expressed as:

$$
f_{4}(x)=\bar{\rho}=\frac{V_{\text {members }}}{V_{\text {core }}}=\frac{\pi D^{2}}{\sin \omega(\sqrt{2} l \cos \omega+2 t)^{2}}
$$

where $V_{\text {members }}$ is the volume of the member, $V_{\text {core }}$ is the volume of the single PLS core, and the function of relative density for the XLS core was $\bar{\rho}=3 \pi D^{2} /\left[4 S_{y}^{2} \sin \omega\right]$, where $\sin \omega=H /(2 l)$, and $S_{y}$ is the length of the XLS core.

\section{The Mathematical Optimization Model and Two Selected Optimization Problems}

Previous studies of LS were mainly on the application of LS's mechanical performances, and few studies used LS in turbine blades to improve both thermal and mechanical performances of blades. We simplified the application of LS on turbine blades as an LS channel with variable aspect ratio and developed a corresponding optimization method. As shown in Figure 1, to set more LS on thin walls of regions " 1 " and " 2 ", bearing load capacity, vibration, and heat transfer performances of turbine blade would be better. However, it would enlarge weight of turbine blades and pressure drop of the channel. Therefore, the optimization method aimed to seek a reasonable topology of LS which can improve both heat transfer and mechanical performances. Herein, based on the given functions which represented relevance between heat transfer and mechanical performances and geometric parameters of the LS channel, a mathematical optimization model was established; two selected optimization problems were proposed; NSGA-II algorithm was used to solve these problems, and optimal structural parameters were obtained.

\subsection{The Mathematical Optimization Model}

An LS channel may improve both heat transfer and mechanical performances of turbine blades. Relevance between heat transfer and mechanical performances and geometric parameters of a LS channel was established, and their functions were obtained. Based on these functions, functional integration design and the multidisciplinary performance requirements were taken into account, and a mathematical optimization design model was established at the start of structural design.

Diameter $(D)$ and inclination angle $(\omega)$ of the LS channel were taken as geometric variables; $N u$, freq1, $E$, and $\bar{\rho}$ were selected as objectives to characterize the performance of 
heat transfer, vibration, load bearing, and light weight, respectively, and the corresponding mathematical optimization model was developed as follows.

Variables of the model are two geometric variables of the LS channel, which are:

$$
x=\left(x_{1}, x_{2}\right)^{\mathrm{T}}=(D, \omega)^{\mathrm{T}}
$$

Three functions of heat transfer and mechanical performance of mathematical optimization model are given as:

$$
\left\{\begin{array}{l}
f_{1}(x)=N u=\frac{1}{N} \sum_{n=1}^{N} N u(n) \\
f_{2}(x)=\text { freq } 1=f(D, \omega) \\
f_{4}(x)=\bar{\rho}=\frac{V_{\text {members }}}{V_{\text {core }}}
\end{array}\right.
$$

Constraints of the variables of the model are:

$$
2 \mathrm{~mm} \leq x_{1} \leq 5 \mathrm{~mm} ; 40^{\circ} \leq x_{2} \leq 70^{\circ}
$$

Additionally, its equivalent elastic modulus represented bearing load capacity of LS channel, and the value of equivalent elastic modulus was taken greater than the value of its crushing strength, which was also a constraint for LS. The function is expressed as:

$$
f_{3}(x)>\sigma
$$

\subsection{Two Selected Optimization Problems}

According to the different emphases of specific engineering applications on turbine blades, two kinds of combinatorial optimization problems were proposed. The optimization problem I (Op-I) was a problem based on $N u$ and $\bar{\rho}$, focusing on the optimization of structural performance of heat transfer and light weight of LS channel. The corresponding mathematical model is as follows:

Op-I:

$$
\begin{gathered}
\operatorname{Max} f_{1}(x)=N u \\
\operatorname{Min} f_{4}(x)=\bar{\rho} \\
\text { s.t. } 2 \mathrm{~mm} \leq x_{1} \leq 5 \mathrm{~mm} \\
40^{\circ} \leq x_{2} \leq 70^{\circ}
\end{gathered}
$$

where "Max" and "Min" mean that the structural performances of heat transfer and light weight of the LS channel should reach relatively maximum and minimum, respectively, and "s.t." refers to the constraint of the optimization problem.

The optimization problem II (Op-II) was a problem based on $N u, \bar{\rho}$, and freq 1 , focusing on the optimization of the structural performances of heat transfer, light weight, and vibration. The corresponding mathematical model is as follows:

Op-II:

$$
\begin{gathered}
\operatorname{Max} f_{1}(x)=N u \\
\operatorname{Min} f_{2}(x)=f r e q 1 \\
\text { s.t. } f_{3}(x)>\sigma \\
2 \mathrm{~mm} \leq x_{1} \leq 5 \mathrm{~mm} \\
40^{\circ} \leq x_{2} \leq 70^{\circ}
\end{gathered}
$$

where "Max" and "Min" mean that the structural performances of heat transfer, light weight, and vibration of LS channel should reach relatively maximum and minimum, respectively. 


\subsection{Establishment and Procedure of Solution for Mathematical Optimization Model}

The ISIGHT2018 optimization software was used to build the mathematical optimization model for PLS and XLS channel. As shown in Figure 6, models of PLS and XLS core were established by SOLIDWORKS; value of freq1 was calculated by ABAQUS; and $N u$, relative density $(\bar{\rho})$, and $E$ were directly calculated by the given functions. Herein, we mainly investigated the heat transfer and mechanical performances of the LS channel. Moreover, in future study, pressure loss, porosity, and friction coefficient of the LS channel can be added at this mathematical optimization model.

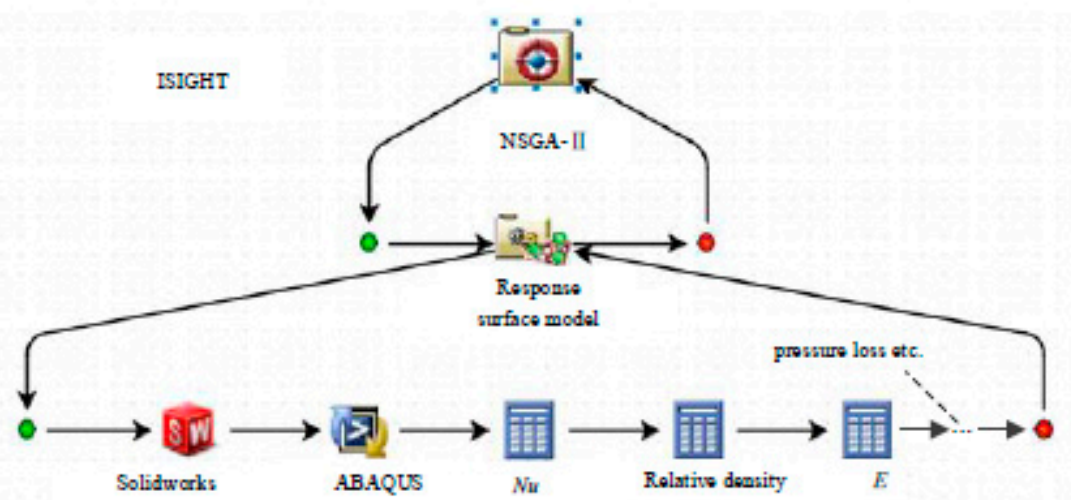

(a) The mathematical optimization model established in ISIGHT

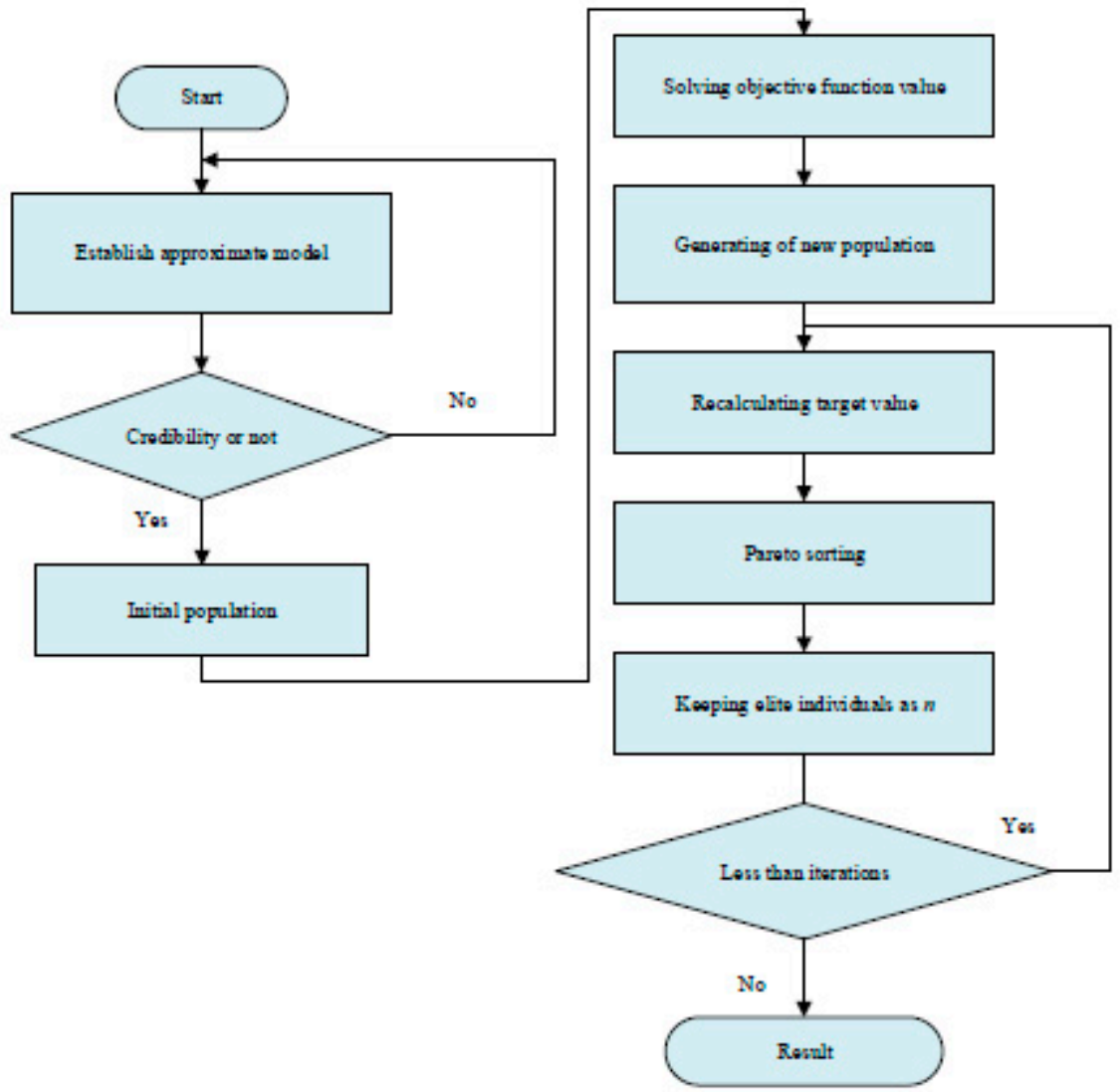

(b) Procedure of optimization with NSGA- II algorithm

Figure 6. Mathematical optimization model establishment and the procedure of optimization: (a) The mathematical optimization model established in ISIGHT; and (b) procedure of optimization with NSGA- II algorithm. 


\subsubsection{Establishment of Approximate Model}

In ISIGHT, model objectives (freq $1, N u$ and $\bar{\rho}$ ) were the input values. Before the optimization work, the relevance between model variables $(D$ and $\omega)$ and these model objectives was established by the third-order response surface model (RSM), as shown in Figure 6a, and RSM was used to establish the approximate model to improve the calculation efficiency. At the same time, in order to make all the test points evenly distributed in the design space, the DOE optimal Latin hypercube (opt. LHD) sampling mode was selected, with the sample number of 50, and the sample number for error analysis was 25 .

The RSM cannot guarantee to pass all the sample points; therefore, there was a certain error compared to the actual model. In order to ensure the calculation accuracy of the approximate model, the fitting accuracy $R^{2}$ was used to verify the accuracy of the approximate model (Table 2).

The calculation formula of fitting accuracy $R^{2}$ is:

$$
R^{2}=\frac{S S_{R}}{S S_{T}}
$$

where $S S_{R}$ represents the sum of regression squares, $S S_{R}=\sum_{l=1}^{k}\left(\hat{y}_{l}-\bar{y}\right)^{2} ; S S_{T}$ represents the sum of total squares, $S S_{T}=\sum_{i=1}^{k}\left(\hat{y}_{i}-\bar{y}\right)^{2} ; \bar{y}$ is the average value of response; $\hat{y}_{l}$ is the predicted value at the design point; $y_{i}$ is the real value of response, and $k$ is the number of sample points.

It can be observed from Table 2 that the fitting accuracy values for the four optimization objectives were all above 0.97 . Therefore, the model can well approximate the actual model, and this model can be used for the following optimization work of the LS channel.

Table 2. Fitting accuracy of approximate models for PLS and XLS.

\begin{tabular}{ccccc}
\hline \multirow{2}{*}{ Structure } & \multicolumn{3}{c}{$\boldsymbol{R}^{\mathbf{2}}$} \\
\cline { 2 - 5 } & $f_{\mathbf{1}}(\boldsymbol{x})$ & $f_{\mathbf{2}}(\boldsymbol{x})$ & $f_{\mathbf{3}}(\boldsymbol{x})$ & $f_{\mathbf{4}}(\boldsymbol{x})$ \\
\hline PLS & 0.99916 & 0.99086 & 0.99013 & 0.98409 \\
XLS & 0.99927 & 0.99240 & 0.98729 & 0.97863 \\
\hline
\end{tabular}

\subsubsection{Optimization Procedure}

As shown in Figure 6a, the NSGA-II algorithm, with good exploration performance, was selected for optimization. The specific procedure is shown in Figure $6 \mathrm{~b}$ and described as follows:

1. At the beginning of the solution, an accurate approximate model was established with RSM.

2. The population was initialized. Value of the objective function was solved.

3. Pareto sorting was carried out to obtain its elite individuals.

4. Step 3 was iterated repeatedly until the optimal solution set was found.

5. At the end of the solution, the optimum results were obtained.

\subsubsection{NSGA-II Algorithm Setting and Stability Verification}

As mentioned above, the NSGA-II algorithm was used to solve the mathematical optimization model of the LS channel, and the PLS channel was used to describe this algorithm as follows:

The specific parameters of this algorithm were set as sizes of population, 80; algebras of heredity, 100; crossover of probability, 0.9; and index for distribution of mutation, 20. Figure 7 reveals that when the sizes of population increased from 12 to 24, the Pareto front tended to be consistent. When the sizes of population were 20, the Pareto fronts of PLS and XLS were basically stable, as shown in Figure 7a. With the increase of algebras of heredity from 20 to 40, the Pareto frontier tended to be consistent. When the algebras 
of heredity were 30, the Pareto fronts of PLS and XLS were basically stable, as shown in Figure $7 \mathrm{~b}$. Therefore, to avoid only obtaining the local optimal solution, and to improve the accuracy of the optimization results, the sizes of population and the algebras of heredity were selected as 20 and 30, respectively.

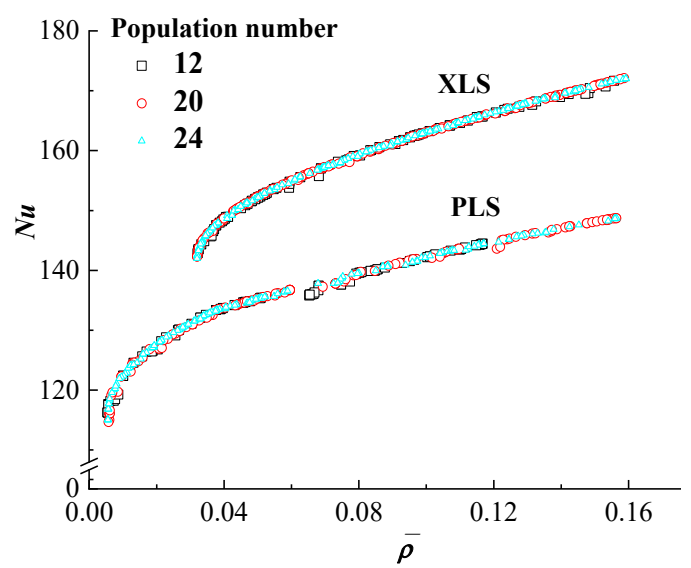

(a) Sizes of population

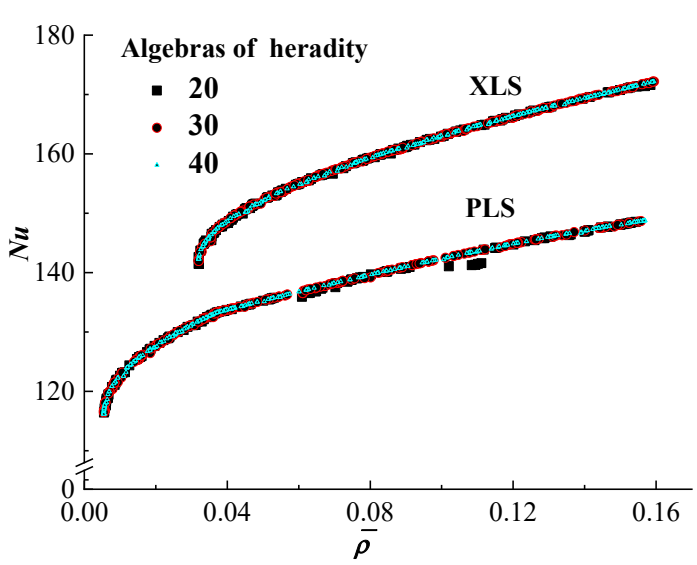

(b) Algebras of heredity

Figure 7. Influence of main parameters of genetic algorithm on the stability: (a) Sizes of population; and (b) algebras of heredity.

\section{Results and Analysis}

In this study, functions representing relevance between heat transfer and mechanical performances and geometric parameters were given. Based on these functions, a mathematical optimization model was built. The given functions were input values of the mathematical optimization model; two selected optimization problems were solved by NSGA-II algorithm, and results are shown as follows.

\subsection{Sensitivity Analysis}

The two selected optimization problems had two and three objectives, respectively, and the values of these objectives were expected to be relatively maximum or minimum. Therefore, the objective of this study was to reveal the law of influence between the objectives and geometric parameters and to obtain a relatively optimal LS structure. The sensitivity between them was analyzed. The overall sensitivity reveals the relations among objectives, and a higher overall sensitivity means that the solution set of the optimization problem is more concentrative. Single sensitivity reveals the law of influence of geometric variables to optimization objectives, and a higher single sensitivity means that change of variables has a larger influence on objectives.

\subsubsection{Overall and Single Sensitivity Analysis for the Results of Op-I}

Figure 7a shows that both for PLS or XLS, the Pareto front was an exponential distribution, approximately. $N u$ of XLS was always bigger than that of PLS, under the same $\bar{\rho}$, as XLS was regarded as two PLS composed together. Thus, the heat conduction of XLS was better than PLS. Tables 3 and 4 show the distribution for the Pareto solutions of $N u$ and $\bar{\rho}$ for Op-I, respectively. It can be found that the Pareto front was mainly concentrated in the region of higher $N u$ both for PLS and XLS. For PLS, the optimal Pareto solutions of $N u$ between 130 and 148 were $73.45 \%$ of the total set of solutions of $N u$. For XLS, the optimal Pareto solutions of $\mathrm{Nu}$ between 150 and 172 were $79.1 \%$ of the total set of solutions of $\mathrm{Nu}$. It can also be found that the set of Pareto solutions of $\bar{\rho}$ were relatively uniform in both PLS and XLS. Therefore, Op-I is more sensitive to $N u$ than to $\bar{\rho}$. 
Table 3. The distribution for Pareto solutions of $N u$ for Op-I.

\begin{tabular}{ccccc}
\hline$N u$ & {$[\mathbf{1 1 6}, \mathbf{1 2 0})$} & {$[\mathbf{1 2 0}, \mathbf{1 3 0})$} & {$[\mathbf{1 3 0 , 1 3 9 )}$} & {$[\mathbf{1 3 9 , \mathbf { 1 4 8 } ]}$} \\
\hline Pareto $(\mathrm{PLS})$ & 23 & 37 & 81 & 85 \\
\hline $\boldsymbol{N u}$ & {$[\mathbf{1 4 1}, \mathbf{1 5 0})$} & {$[\mathbf{1 5 0 , 1 6 0 )}$} & {$[\mathbf{1 6 0 , 1 7 2}]$} & - \\
\hline Pareto $(\mathrm{XLS})$ & 46 & 76 & 98 & - \\
\hline
\end{tabular}

Table 4. The distribution for Pareto solutions of $\bar{\rho}$ for Op-I.

\begin{tabular}{cccccc}
\hline$\overline{\boldsymbol{\rho}} \mathbf{( \% )}$ & {$[\mathbf{0 . 5}, \mathbf{3})$} & {$[\mathbf{3}, \mathbf{6})$} & {$[\mathbf{6}, \mathbf{9 )}$} & {$[\mathbf{9}, \mathbf{1 2})$} & {$[\mathbf{1 2}, \mathbf{1 5}]$} \\
\hline Pareto (PLS) & 65 & 51 & 33 & 38 & 39 \\
\hline Pareto (XLS) & - & 82 & 56 & 39 & 43 \\
\hline
\end{tabular}

As discussed above, under the same $\bar{\rho}$, Nu of XLS was greater than Nu of PLS, so only XLS was selected for the analysis of single sensitivity.

As shown in Figure 7b, the optimal solutions of $D$ concentrated between $2.3 \mathrm{~mm}$ and $2.9 \mathrm{~mm}$, and the total distribution was relatively uniform. Figure $8 \mathrm{c}$ shows that the optimal solution of $\omega$ was between $52^{\circ}$ and $66^{\circ}$, which was mainly concentrated between $58^{\circ}$ and $66^{\circ}$. The diffusion level of $\omega$ was bigger than $D$. Therefore, $D$ had a greater impact on Op-I than $\omega$. In addition, the correlation coefficient $r$ was used to represent the single sensitivity of each parameter, and its calculation formula is as follows:

$$
r_{X Y}=\frac{\sum(X-\bar{X})(Y-\bar{Y})}{\sqrt{\sum(X-\bar{X})^{2}} \sqrt{\sum(Y-\bar{Y})^{2}}}=\frac{\sum x y}{\sqrt{\sum x^{2}} \sqrt{\sum y^{2}}}=\frac{S_{X Y}}{S_{X} S_{Y}}
$$

where $x=X-\bar{X}, y=Y-\bar{Y}, S_{X Y}$ is the total variation of samples, $S_{X Y}=$ $\sum(X-\bar{X})(Y-\bar{Y}) /(n-1) ; S_{X}$ is the standard deviation of $X$ sample, $S_{X}=$ $\sqrt{\sum(X-\bar{X})^{2} /(n-1)} ; S_{Y}$ is the standard deviation of $Y$ sample, and $S_{Y}=$ $\sqrt{\sum(Y-\bar{Y})^{2} /(n-1)}$. Among them, the positive sign indicates a positive correlation, and the negative sign indicates a negative correlation.

At the same time, the larger these values, the stronger is the correlation between two variables, and the stronger is the single sensitivity, and vice versa.

Figure $8 \mathrm{~d}$ shows that the set of Pareto optimization solutions of $\omega$ was the most sensitive for $\mathrm{Nu}$, while the set of Pareto optimization solutions of $D$ was the most sensitive for $\bar{\rho}$.

In conclusion, the overall performance of Op-I was that the objective function of $\mathrm{Nu}$ had the highest sensitivity for Op-I, $\omega$ had the highest correlation or sensitivity for $N u$, and $D$ had the highest correlation or sensitivity for $\bar{\rho}$. 


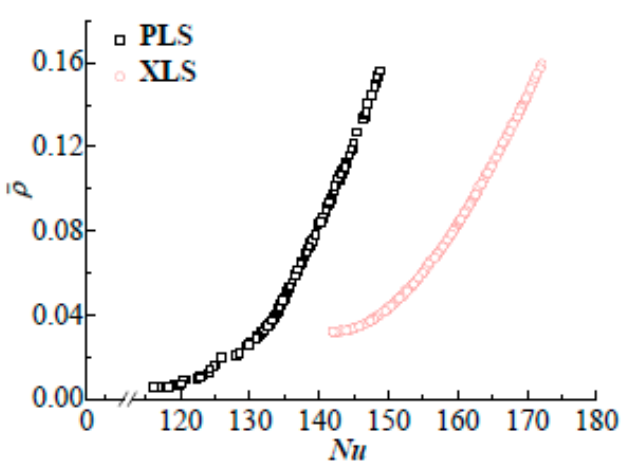

(a) Pareto fronts of Op-I

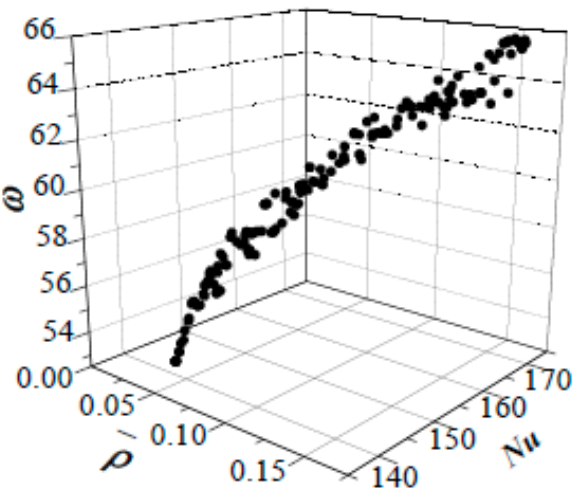

(c) Pareto solutions of Op-I for $N u$ and $\bar{\rho}$ based on $\omega$

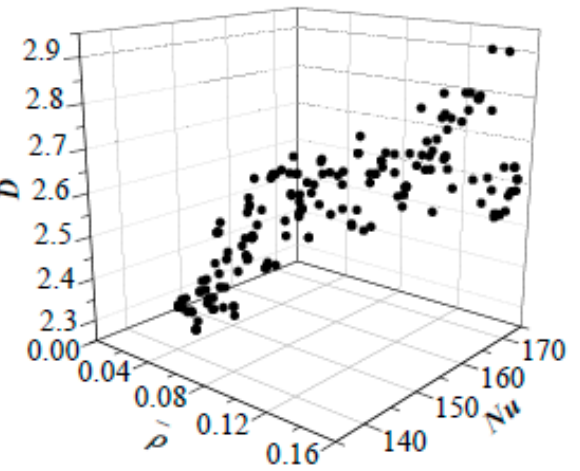

(b) Pareto solutions of Op-I for $N u$ and $\bar{\rho}$ based on $D$

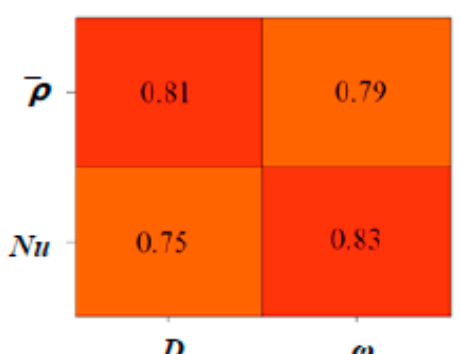

(d) Correlation between various parameters $(D, \omega)$ and optimization objectives $(N u, \bar{\rho})$

Figure 8. Overall and single sensitivity analysis for Op-I of XLS: (a) Pareto fronts of Op-I; (b) Pareto solutions of Op-I for $N u$ and $\bar{\rho}$ based on $D$; (c) Pareto solutions of Op-I for $N u$ and $\bar{\rho}$ based on $\omega$; and (d) correlation between various parameters $(D, \omega)$ and optimization objectives $(N u, \bar{\rho})$.

\subsubsection{Overall and Single Sensitivity for the Results of Op-II}

Figure 9a shows the Pareto fronts of Op-II. The Pareto fronts distributed at a curved surface, approximately. The values of freq 1 had a great impact on the other two parameters. At the same time, the optimal solutions of the freq 1 were all concentrated between $269 \mathrm{~Hz}$ and $271 \mathrm{~Hz}$. Therefore, freq 1 was the highest for the overall sensitivity of Op-II.

Tables 5 and 6 show that the set of Pareto solution of XLS was mainly concentrated in the region with higher $N u$. The optimal solutions with $N u$ between 140 and 172 were $95.3 \%$ of the total set of solutions of $\mathrm{Nu}$. The optimal solutions with $\bar{\rho}$ between 3 and 9 were $56.9 \%$ of the total set of solutions of $\bar{\rho}$. Therefore, the overall sensitivity of $N u$ was higher than $\bar{\rho}$. Thus, Op-II was more sensitive to freq1 than to $N u$ and least sensitive to $\bar{\rho}$.

Table 5. The distribution for Pareto solutions of $N u$ for Op-II.

\begin{tabular}{ccccc}
\hline$N \boldsymbol{u}$ & {$[\mathbf{1 3 8}, \mathbf{1 4 0})$} & {$[\mathbf{1 4 0 , \mathbf { 1 5 0 } )}$} & {$[\mathbf{1 5 0 , \mathbf { 1 6 0 } )}$} & {$[\mathbf{1 6 0 , \mathbf { 1 7 2 } ]}$} \\
\hline Pareto $(\mathrm{XLS})$ & 18 & 86 & 108 & 173 \\
\hline
\end{tabular}

Table 6. The distribution for Pareto solutions of $\bar{\rho}$ for Op-II.

\begin{tabular}{ccccc}
\hline$\overline{\boldsymbol{\rho}}(\mathbf{\%})$ & {$[\mathbf{3}, \mathbf{6})$} & {$[\mathbf{6}, \mathbf{9})$} & {$[\mathbf{9 , 1 2})$} & {$[\mathbf{1 2}, \mathbf{1 5}]$} \\
\hline Pareto $(\mathrm{XLS})$ & 149 & 70 & 70 & 96 \\
\hline
\end{tabular}




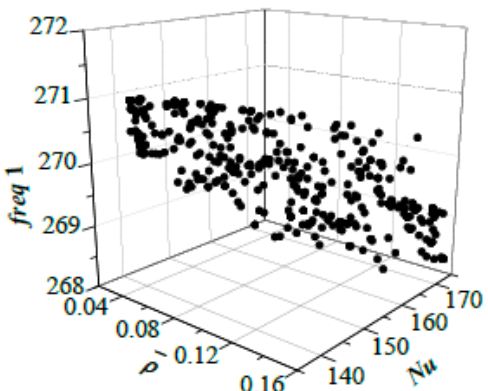

(a) Pareto fronts of $\mathrm{Op}-\mathrm{II}$

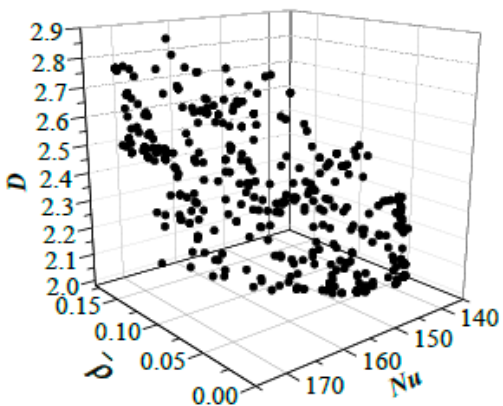

(c) Pareto solutions of Op-II for $N u$ and $\bar{\rho}$ based on $D$

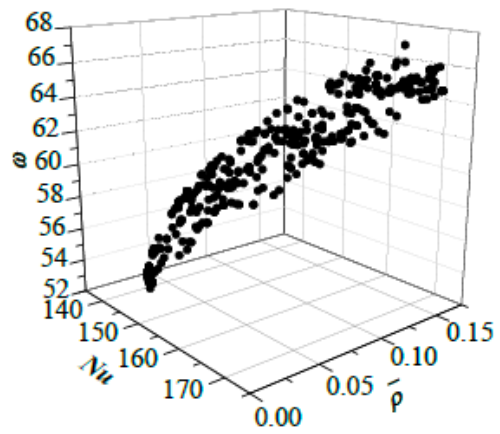

(e) Pareto solutions of Op-II for Nu and $\bar{\rho}$ based on $\omega$

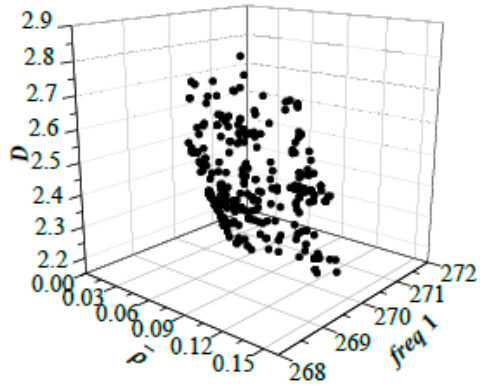

(b) Pareto solutions of Op-II for $\bar{\rho}$ and freq1 based on $D$

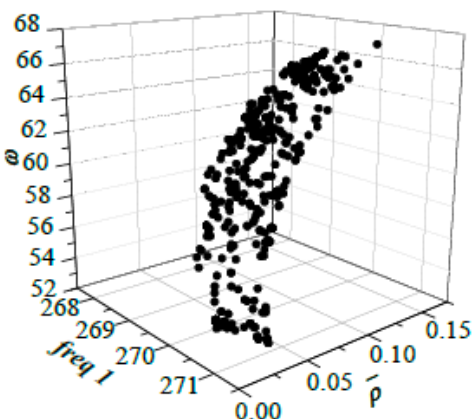

(d) Pareto solutions of Op-II for $\bar{\rho}$ and freq1 based on $\omega$

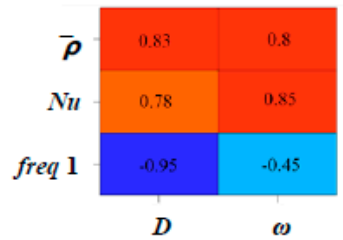

(f) Correlation between various parameters $(D, \omega)$ and

optimization objectives $(\mathrm{Nu}, \bar{\rho})$

Figure 9. Overall and single sensitivity analysis for Op-II of XLS: (a) Pareto fronts of Op-II; (b) Pareto solutions of Op-II for $\bar{\rho}$ and freq 1 based on $D$; (c) Pareto solutions of Op-II for $N u$ and $\bar{\rho}$ based on $D$; (d) Pareto solutions of Op-II for $\bar{\rho}$ and freq1 based on $\omega$; (e) Pareto solutions of Op-II for $N u$ and $\bar{\rho}$ based on $\omega$; and (f) correlation between various parameters $(D, \omega)$ and optimization objectives $(N u, \bar{\rho})$.

It can be found from Figure $9 \mathrm{~b}, \mathrm{c}$ that the optimal solutions of $D$ concentrated between $2.3 \mathrm{~mm}$ and $2.9 \mathrm{~mm}$, were generally distributed at a curved surface, and were relatively uniform. As shown in Figure 9d,e, the optimal solution of $\omega$ was between $52^{\circ}$ and $66^{\circ}$. Figure $9 \mathrm{f}$ reveals that $D$ and $\omega$ had negative correlation with freq1. $N u$ was more sensitive to $\omega$ than to $D$, while $\bar{\rho}$ was more sensitive to $D$ than to $\omega$. However, freq 1 was not sensitive to $D$ and $\omega$, which means that the change in $D$ and $\omega$ has little effect on freq1. freq 1 may be most sensitive to $H$ (height of cooling channel), while $H$ herein remains unchanged.

\subsubsection{The Representative Function for Optimization Results of Op-I and Op-II}

As the set of Pareto optimization solutions obtained above were a series of discrete points, and the value in practical application was not included in these discrete points, it was necessary to provide a continuous set of optimization solution as a reference to the actual situation.

$$
N u=a \cdot e^{b \bar{\rho}}+c
$$


Figure 10a,b show that the distribution form of the Pareto set of solutions for $\mathrm{Nu}$ and $\bar{\rho}$ in the two optimization problems presented strong convexity. Therefore, the first-order exponential function was used to fit them. The function equation is shown in Equation (33), and the values of each coefficient in the formula are shown in Table 7.

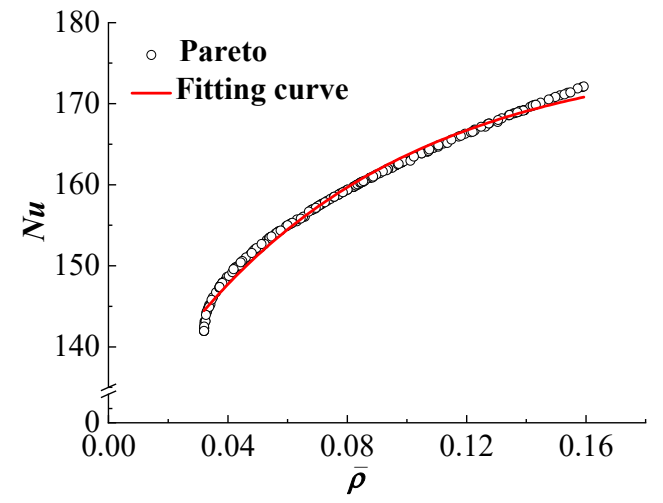

(a) Op-I

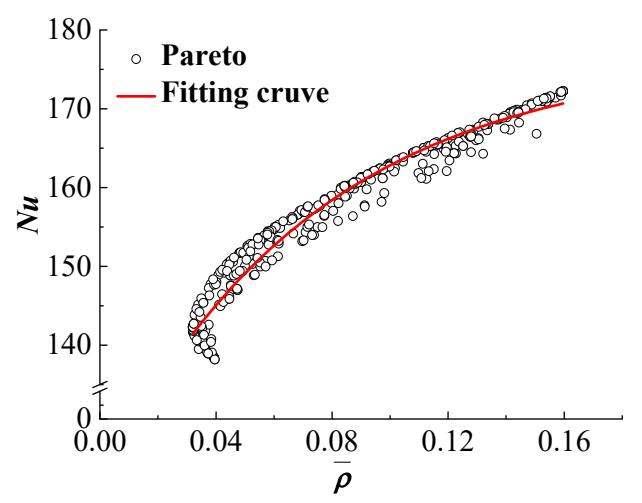

(b) Op-II

Figure 10. Pareto fronts and fitting curves of XLS of (a) Op-I and (b) Op-II.

Table 7. Coefficients of the set of Pareto optimized solutions in fitting function.

\begin{tabular}{cccc}
\hline Coefficient & $\boldsymbol{a}$ & $\boldsymbol{b}$ & $\boldsymbol{c}$ \\
\hline Op-I & -49.434 & -13.253 & 176.796 \\
Op-II & -54.888 & -13.542 & 176.984 \\
\hline
\end{tabular}

\subsubsection{Optimization Results Comparison}

Table 8 shows the comparison between the initial model and the optimized model. In order to reveal the performance improvement of the optimized structure compared with the original structure, a representative Pareto solution set of Op-I or Op-II was selected. As can be found from Table 8, for Op-I, when the $\mathrm{Nu}$ reached 150, it was about $24.1 \%$ higher than that of the initial model. At the same time, the relative density decreased by $31 \%$. For Op-II, when the $N u$ reached 160 , it was $28.8 \%$ higher than that of the initial model, and the relative density was basically the same as the initial model. Therefore, the optimization results were very effective.

Table 8. Comparison of the optimization results.

\begin{tabular}{ccccc}
\hline Model & $\boldsymbol{D}$ & $\boldsymbol{\omega}$ & $\boldsymbol{N u}$ & $\overline{\boldsymbol{\rho}}$ \\
\hline Initial model & 2 & $45^{\circ}$ & 124.5 & 0.084 \\
Op-I model & 2.5 & $58.8^{\circ}$ & 154.5 & 0.058 \\
Op-II model & 2.6 & $61^{\circ}$ & 160.3 & 0.084 \\
\hline
\end{tabular}

\subsection{Validation of Mechanical and Heat Transfer Performances}

As shown in Table 8, a group of optimal structural parameters of the XLS channel to develop a relevant XLS model were obtained, which had relatively excellent mechanical and heat transfer performances by the mathematical optimization model. Two validation methods were employed to verify the accuracy of this mathematical optimization model.

\subsubsection{Validation of Bearing Load Performance}

Although function of bearing load performance was used as a constraint, its value can be obtained by corresponding experiment to verify the accuracy of the mathematical optimization model. Equivalent elastic modulus $(E)$ was used to evaluate bearing load capacity of XLS cores. A relevant experiment was developed to obtain $E$. 
Firstly, both the initial model and the optimal model were built. Because XLS has the property of periodicity, only a single XLS core was made, as shown in Figure 11a, and two side walls of LS core were removed. Secondly, according to the GB/T 1041-2008 test standard, the unidirectional compression test of the structure was carried out by a ctm2000 universal material testing machine. The pre-cyclic loading method was adopted in the experiment, and the loading rate was $0.5 \mathrm{~mm} / \mathrm{min}$. The force displacement curve of the XLS core was obtained (Figure 11b). It can be found that the black curve was the force displacement curve of the initial model of the XLS core, and the maximum force was $8543.267 \mathrm{~N}$, which was converted into the elastic modulus of 680.196 MPa. The theoretical calculation value of equivalent elastic modulus was $830.265 \mathrm{MPa}$. The error between the maximum valve of the XLS core and the theoretical calculation value was $10.3 \%$. Therefore, $E$ can accurately evaluate the bearing load capacity of the XLS core. Moreover, it can be observed from Figure 11b that the maximum bearing capacities of the optimization result of Op-I and Op-II were 11,089.41 N and 12,404.22 N, respectively. Compared with the initial model, the maximum bearing load capacity of the optimized structure was significantly improved. From the results of Figure 10c, the maximum bearing load capacity for the optimal structure of Op-I was increased by $29.8 \%$ compared to that of the initial model. The maximum capacity of bearing load for the optimal structure of Op-II was increased by $45.2 \%$ compared to that of the initial model. Therefore, the mathematical optimization model was accurate for bearing load performance.

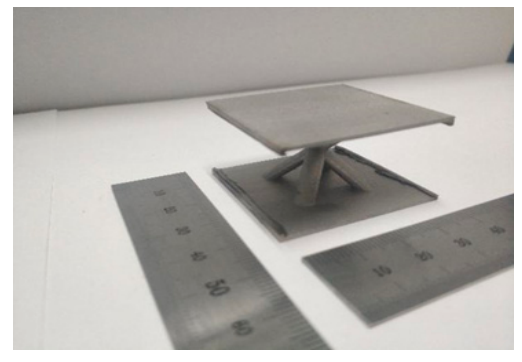

(a) XLS core made by IN 718 (shown in Table 1)

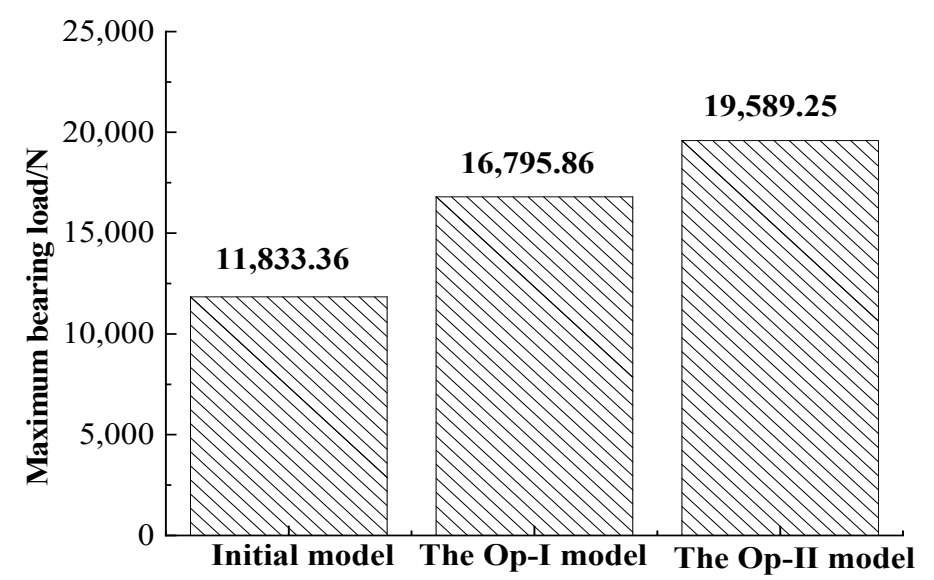

(c) Comparison for the maximum bearing load of XLS

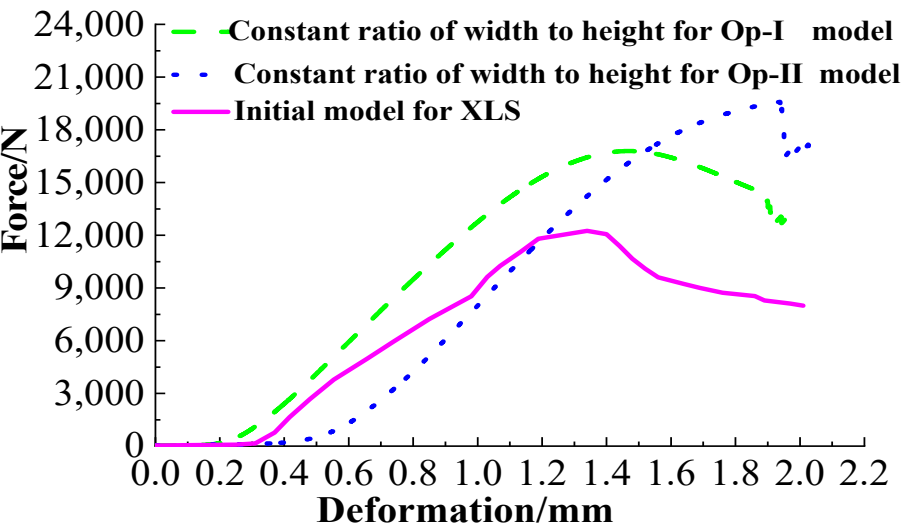

(b) Force displacement curves of XLS

Figure 11. Validation XLS model and validation results: (a) XLS core; (b) force displacement curves; and (c) comparison for the maximum bearing load. 


\subsubsection{Validation of Heat Transfer Performance}

Nusselt number $(\mathrm{Nu})$ was used to evaluate heat transfer performance of the XLS channel. Relevant numerical simulation was developed to obtain values of $N u$ for both the initial model and the optimization models to verify accuracy of the mathematical optimization model as follows.

As shown in Figure 2, the XLS model was established for numerical simulation. The grid of XLS was finished by ICEM CFD. The commercial software CFX18.0 was used for simulation, and a standard $k-\varepsilon$ model was used for turbulent model. The pressure based on simple algorithm was adopted, and the second-order upwind scheme was selected.

The boundary conditions were as follows. The inlet was a mass flow inlet of $7.67 \times 10^{-3} \mathrm{Kg} / \mathrm{s}$, the inlet $R e$ was 10,000 , the inlet air temperature was set at $300 \mathrm{~K}$, the turbulent degree was $5 \%$, and the heat flux $q$ of the heated wall was constant at $3000 \mathrm{~W} / \mathrm{m}^{2}$. The data processing methods involved were as follows:

The definition of Re:

$$
R e=\frac{D_{h} u_{m} \rho}{\mu}=\frac{4 \dot{m}}{\pi D_{h} \mu}
$$

The definition of average $\mathrm{Nu}$ :

$$
N u=\frac{q H}{\left(T_{w}-T_{a i r}\right) k_{f}}
$$

where $d_{h}$ is the hydraulic diameter of the lattice channel, $d_{h}=50.33 \mathrm{~mm} ; q$ is target heat flux; $T_{W}$ is target surface temperature; $T_{\text {air }}$ is inlet airflow temperature; $H$ is height of channel; $\lambda$ is air thermal conductivity; $\mu$ is aerodynamic viscosity, and $\dot{m}$ is mass flow rate.

In order to verify the reliability of the model, the experimental data of XLS from Kim et al. [38] was selected. The $N u$ values under different turbulent models are shown in Figure 12. It can be seen that the values of the standard $k-\varepsilon$ turbulent model were very consistent with the experimental values, with an error of $9.6 \%$. Therefore, the standard $k-\varepsilon$ was used in the subsequent numerical simulation.

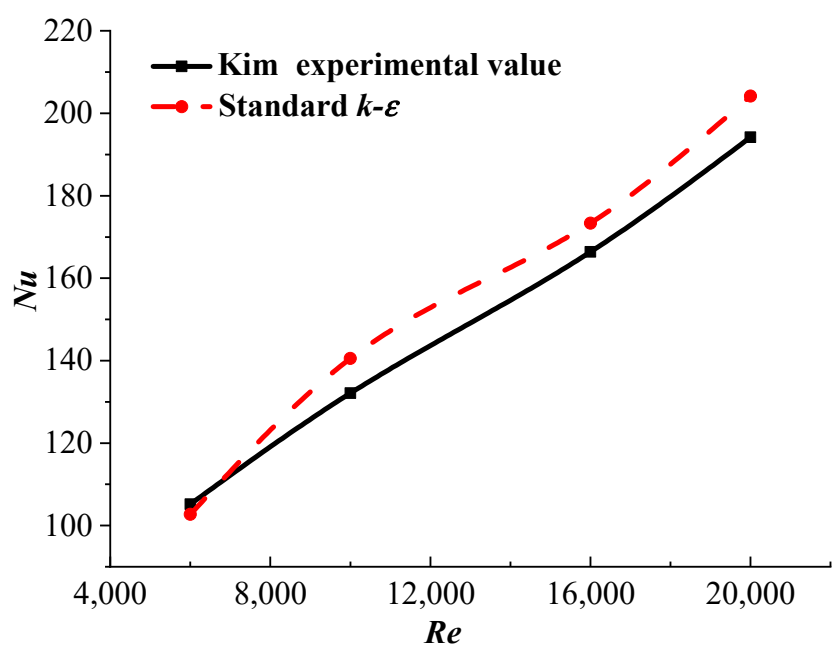

Figure 12. Validation of model.

Simulation results for fluid flow and heat transfer of the XLS channel were obtained. Figure 13a-c reveal that the XLS had a great disturbing effect on the air flow in the channel, and the flow velocity in the rear along the flow direction was significantly reduced. For the initial model, because the diameter of the member was smaller than that of the optimal structure, the low velocity area formed behind the member was small. For the Op-I model and the Op-II model, due to the increase of member diameter, airflow disturbance in the channel was all strengthened. Figure $13 \mathrm{~d}-\mathrm{f}$ show that the distribution of $N u$ of the optimal 
model was more uniform than that of the initial model, and Figure $13 \mathrm{~g}$ shows that the $\mathrm{Nu}$ of the initial model obtained by the numerical calculation was close to the calculated value obtained by the optimized fin method. Moreover, pressure drops under the condition of $R e=10,000$ were $302.179 \mathrm{~Pa}, 294.323 \mathrm{~Pa}$, and 302.558 Pa for the initial model, the model of Op-I, and the model of Op-II, respectively. The pressure drops of these three models were similar, and acceptable for the LS channel which had only five simple LS cores. Therefore, pressure drop was not considered as a main parameter in this study.

Therefore, the mathematical optimization model was accurate and reasonable for the heat transfer performance.

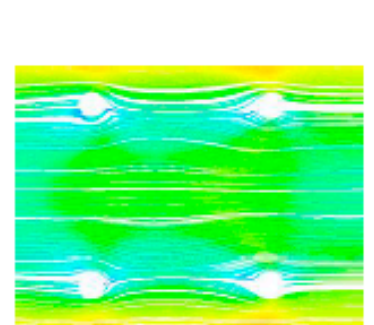

(a) Initial model

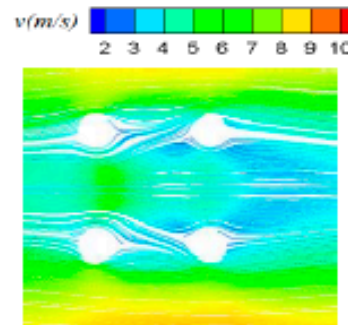

(b) Model of Op-I

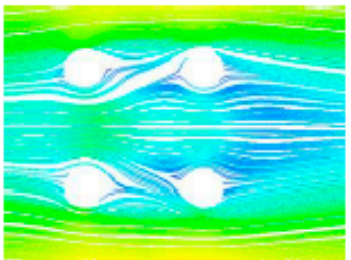

(c) Model of Op-II

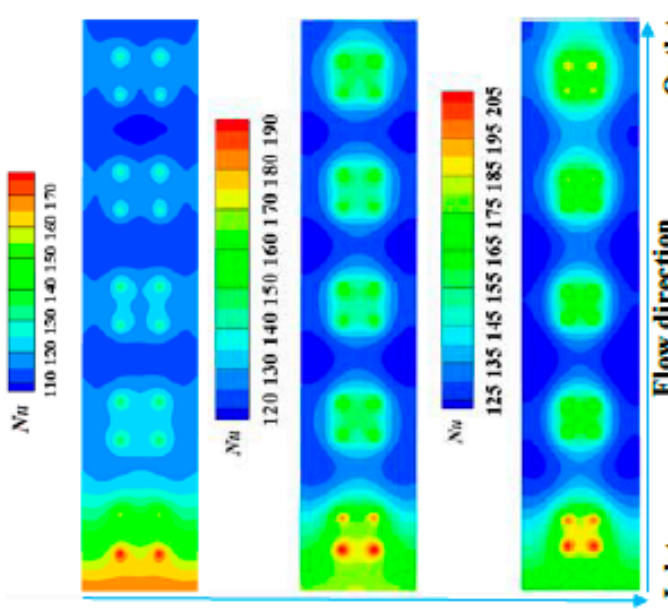

Direction of width

(d) Initial model

(e) Model of Op-I

(f) Model of Op-II

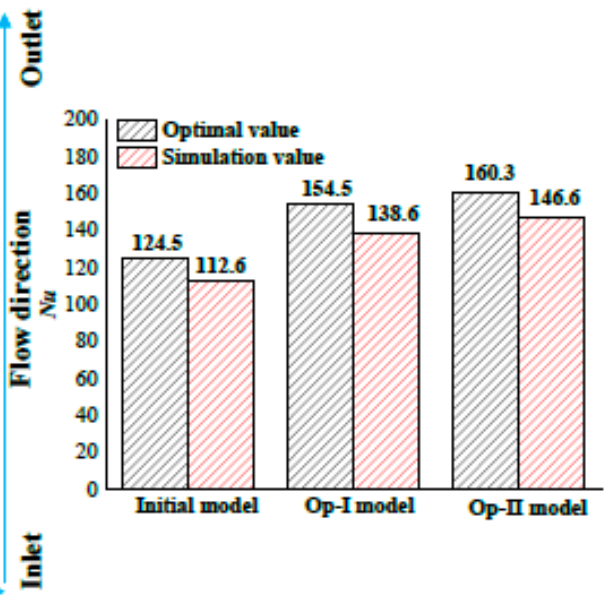

(g) Comparison of $\mathrm{Nu}$ in different models

Figure 13. Streamline of the target surface, $N u$ distribution of the target surface, and $N u$ comparison: (a) Initial model; (b) model of Op-I; (c) model of Op-II; (d) initial model; (e) model of Op-I; (f) model of Op-II; and (g) comparison of $\mathrm{Nu}$ in different models.

\section{Conclusions}

1. The present study established a mathematical optimization model based on LS used in thin walls of turbine blades, which was simplified as an LS channel using an integral optimization design method. Two selected optimization problems (Op-I and Op-II) were proposed to investigate optimum structures of LS, and the optimal results calculated by NSGA-II algorithm were proved to be accurate and reasonable.

2. For Op-I ( $N u$ and $\bar{\rho}$ were the objectives), the overall sensitivity of $D$ and $\omega$ for $N u$ was higher than $\bar{\rho}$. The single sensitivity of $D$ for $\bar{\rho}$ was higher than $\mathrm{Nu}$; the single sensitivity of $\omega$ for $N u$ was higher than $\bar{\rho}$. Compared to the initial LS, $N u$ increased by $24.1 \%$ and $\bar{\rho}$ decreased by $31 \%$, respectively. The optimal structural parameters were $2.3 \mathrm{~mm} \leq D \leq 2.9 \mathrm{~mm}$, and $52^{\circ} \leq \omega \leq 66^{\circ}$.

3. For Op-II (Nu, freq1, and $\bar{\rho}$ were the objectives), the overall sensitivity of $D$ and $\omega$ for the objectives was ranked as freq $1, N u$, and $\bar{\rho}$. The single sensitivity of $D$ for the objectives was ranked as freq $1, \bar{\rho}$, and $N u$; the single sensitivity of $\omega$ for the objectives was ranked as $N u, \bar{\rho}$ and freq1. Compared to the initial LS, $N u$ increased by $28.8 \%$, 
while freq 1 and $\bar{\rho}$ were almost unchanged. The optimum structural parameters were $2.0 \mathrm{~mm} \leq D \leq 3.5 \mathrm{~mm}$, and $56^{\circ} \leq \omega \leq 70^{\circ}$.

4. The fitting function of Pareto fronts of Op-I and Op-II was obtained, which may provide guidance for structural parameters design for LS channels used in turbine blades.

Author Contributions: Conceptualization, L.X. (Liang $\mathrm{Xu}$ ) and Q.S.; methodology, Q.S. and L.X. (Lei Xi); software, Q.S. and L.X. (Lei Xi); validation, L.X. (Liang Xu), Q.S. and Q.R.; formal analysis, L.X. (Liang $\mathrm{Xu}$ ); investigation, Q.S.; resources, L.X. (Liang $\mathrm{Xu}$ ); data curation, Q.R.; writing-original draft preparation, Q.S.; writing—review and editing, Q.S.; visualization, L.X. (Liang Xu); supervision, J.G., L.X. (Liang Xu) and Y.L.; project administration, L.X. (Liang Xu); funding acquisition, L.X. (Liang $\mathrm{Xu}$ ). All authors have read and agreed to the published version of the manuscript.

Funding: This research was funded by the National Key R\&D Program of China, grant number 2018YFB1106400, the National Natural Science Foundation of China, grant number 51876157; Natural Science Foundation of Shaanxi Province in China, grant number 2019JM-096.

Institutional Review Board Statement: Not applicable.

Informed Consent Statement: Not applicable.

Data Availability Statement: Not applicable.

Conflicts of Interest: The authors declare no conflict of interest.

\section{References}

1. Evans, A.G.; Hutchinson, J.W.; Ashby, M.F. Multi-functionality of Cellular Metal Systems. Prog. Mater. Sci. 1999, 43, 171-221. [CrossRef]

2. Wadley Haydn, N.G. Multifunctional periodic cellular metals. Philos. Trans. R. Soc. A Math. Phys. Eng. Sci. 2006, 364, 31-68. [CrossRef] [PubMed]

3. Gibson, R.F. A review of recent research on mechanics of multifunctional composite materials and structures. Compos. Struct. 2010, 92, 2793-2810. [CrossRef]

4. Schaedler, T.A.; Jacobsen, A.J.; Torrents, A. Ultralight metallic micro lattices. Science 2011, 334, 962-965. [CrossRef]

5. Xiong, J.; Mines, R.; Ghosh, R.; Vaziri, A.; Ma, L.; Ohrndorf, A.; Christ, H.-J.; Wu, L.Z. Advanced micro-lattice materials. Adv. Eng. Mater. 2015, 17, 1253-1264. [CrossRef]

6. Han, J.C.; Huh, M. Recent studies in turbine blade internal cooling. Heat Transf. Res. 2010, 41, 803-828.

7. Kim, T.; Hodson, H.P.; Lu, T.J. Fluid-flow and end-wall heat-transfer characteristics of an ultralight lattice-frame material. Int. J. Heat Mass Transf. 2004, 47, 1129-1140. [CrossRef]

8. Yun, S.; Kwon, J.; Lee, D.; Shin, H.H.; Kim, Y. Heat transfer and stress characteristics of additive manufactured FCCZ lattice channel using thermal fluid-structure interaction model. Int. J. Heat Mass Transf. 2020, 149, 119187. [CrossRef]

9. Lebaal, N.; Zhang, Y.; Demoly, F.; Roth, S.; Gomes, S.; Bernard, A. Optimised lattice structure configuration for additive manufacturing. CIRP Ann. 2019, 68, 117-120. [CrossRef]

10. Plocher, J.; Panesar, A. Review on design and structural optimization in additive manufacturing: Towards next-generation lightweight structures. Mater. Des. 2019, 183, 108164. [CrossRef]

11. Wang, J.; Evans, A.G.; Dharmasena, K.; Wadley, H.N.G. On the performance of truss panels with Kagomé cores. Int. J. Solids Struct. 2003, 40, 6981-6988. [CrossRef]

12. Zok, F.W.; Waltner, S.A.; Wei, Z.; Rathbun, H.J.; McMeeking, R.M.; Evans, A.G. A protocol for characterizing the structural performance of metallic sandwich panels: Application to pyramidal truss cores. Int. J. Solids Struct. 2004, 41, 6249-6271. [CrossRef]

13. Lim, J.-H.; Kang, K.J. Mechanical behavior of sandwich panels with tetrahedral and Kagome truss cores fabricated from wires. Int. J. Solids Struct. 2006, 43, 5228-5246. [CrossRef]

14. Feng, L.-J.; Wu, L.-Z.; Yu, G.-C. An Hourglass truss lattice structure and its mechanical performances. Mater. Des. 2016, 99, 581-591. [CrossRef]

15. Hanks, B.; Berthel, J.; Frecker, M.; Simpson, T.W. Mechanical properties of additively manufactured metal lattice structures: Data review and design interface. Addit. Manuf. 2020, 35, 101301. [CrossRef]

16. Hoang, V.N.; Tran, P.; Vu, V.T.; Nguyen-Xuan, H. Design of lattice structures with direct multiscale topology optimization. Compos. Struct. 2020, 252, 112718. [CrossRef]

17. Zhang, J.; Yanagimoto, J. Topology optimization of microlattice dome with enhanced stiffness and energy absorption for additive manufacturing. Compos. Struct. 2021, 255, 112889. [CrossRef]

18. Wu, Q.; Ma, L.; Wu, L.; Xiong, J. A novel strengthening method for carbon fiber composite lattice truss structures. Compos. Struct. 2016, 153, 585-592. [CrossRef]

19. Maes, V.K.; Pavlov, L.; Sahak, M. An efficient semi-automated optimisation approach for (grid-stiffened) composite structures: Application to Ariane 6 Interstage. Compos. Struct. 2019, 209, 1042-1049. [CrossRef] 
20. Meng, L.; Qiu, X.; Gao, T.; Li, Z.; Zhang, W. An inverse approach to the accurate modelling of 3D-printed sandwich panels with lattice core using beams of variable cross-section. Compos. Struct. 2020, 247, 112363. [CrossRef]

21. Liu, J.S.; Lu, T.J. Multi-objective and multi-loading optimization of ultralightweight truss materials. Int. J. Solids Struct. 2004, 41, 619-635. [CrossRef]

22. Valdevit, L.; Hutchinson, J.W.; Evans, A.G. Structurally optimized sandwich panels with prismatic cores. Int. J. Solids Struct. 2004 41, 5105-5124. [CrossRef]

23. Valdevit, L.; Pantano, A.; Stone, H.A.; Evans, A.G. Optimal active cooling performance of metallic sandwich panels with prismatic cores. Int. J. Heat Mass Transf. 2006, 49, 3819-3830. [CrossRef]

24. Chen, M.J.; Pei, Y.M.; Fang, D.N. Multi-objective optimization design of radar absorbing sandwich structure. Appl. Math. Mech. 2010, 31, 339-348. [CrossRef]

25. Roper, C.S. Multiobjective optimization for design of multifunctional sandwich panel heat pipes with micro-architected truss cores. Int. J. Heat Fluid Flow 2011, 32, 239-248. [CrossRef]

26. Ju, S.; Shenoi, R.A.; Jiang, D.; Sobey, A.J. Multi-parameter optimization of lightweight composite triangular truss structure based on response surface methodology. Compos. Struct. 2013, 97, 107-116. [CrossRef]

27. Moon, S.K.; Tan, Y.E.; Yoon, Y.-J.; Hwang, J. Application of 3D printing technology for designing light-weight unmanned aerial vehicle wing structures. Int. J. Precis. Eng. Manuf. Green Technol. 2014, 1, 223-228. [CrossRef]

28. Meng, J.; Liao, L.F.; Li, D.; Cao, Y.; Yang, L.Y.; Chen, Y.Y. Topology Optimization Method Research on Hollow Wide-chord Fan Blade of a High-bypass Turbofan Engine. Procedia Eng. 2015, 99, 1228-1233. [CrossRef]

29. Fazilati, J.; Alisadeghi, M. Multi-objective crashworthiness optimization of multi-layer honeycomb energy absorber panels under axial impact. Thin-Walled Struct. 2016, 107, 197-206. [CrossRef]

30. Xu, X.; Jiang, Y.; Pueh Lee, H. Multi-objective optimal design of sandwich panels using a genetic algorithm. Eng. Optim. 2017, 49, 1665-1684. [CrossRef]

31. Bai, L.; Xiong, F.; Chen, X.; Yi, C.; Zhang, J.; Chen, R. Multi-objective structural optimization design of Ti6AL4V lattice structure formed by SLM. J. Mech. Eng. 2018, 54, 156-165. [CrossRef]

32. Smardzewski, J.; Wojciechowski, K.W. Response of wood-based sandwich beams with three-dimensional lattice core. Compos. Struct. 2019, 216, 340-349. [CrossRef]

33. Zhao, J.; Zhang, M.; Zhu, Y.; Li, X.; Wang, L.; Hu, C. Concurrent optimization of additive manufacturing fabricated lattice structures for natural frequencies. Int. J. Mech. Sci. 2019, 163, 105153. [CrossRef]

34. Takezawa, A.; Zhang, X.; Kato, M.; Kitamura, M. Method to optimize an additively-manufactured functionally-graded lattice structure for effective liquid cooling. Addit. Manuf. 2019, 28, 285-298. [CrossRef]

35. Baykasoğlu, A.; Baykasoğlu, C.; Cetin, E. Multi-objective crashworthiness optimization of lattice structure filled thin-walled tubes. Thin-Walled Struct. 2020, 149, 106630. [CrossRef]

36. Gao, L.; Sun, S.; Zhao, Y.; Sun, Y. Thermostructural multiobjective optimization of a composite sandwich panel with lattice truss cores. Numer. Heat Transf. Part B Fundam. 2016, 70, 233-250. [CrossRef]

37. Liang, X.; Lei, X.; Zhen, Z.; Jianmin, G.; Yunlong, L. Numerical prediction of heat loss from a test ribbed rectangular channel using the conjugate calculations. Int. Commun. Heat Mass Transf. 2018, 96, 98-108. [CrossRef]

38. Kim, T.; Hodson, H.P.; Lu, T.J. Contribution of vortex structures and flow separation to local and overall pressure and heat transfer characteristics in an ultralightweight lattice material. Int. J. Heat Mass Transf. 2005, 48, 4243-4264. [CrossRef]

39. Jiang, P.X.; Li, M.; Lu, T.J.; Yu, L.; Ren, Z.P. Experimental research on convection heat transfer in sintered porous plate channels. Int. J. Heat Mass Transf. 2004, 47, 2085-2096. [CrossRef]

40. Li, B.; Zhang, Q.; Lu, T. Dynamic performance of truss core sandwich structures based on modal analysis experiments. Chin. J. Solid Mech. 2008, 29, 373-378. (In Chinese)

41. Li, S.; Yang, J.; Wu, L.; Yu, G.; Yang, L.; Qu, J. Influence of boundary conditions and truss inclination angles on vibration characteristics of the hourglass lattice structure. J. Harbin Eng. Univ. 2019, 40, 878-885. (In Chinese) 